\title{
Global impacts of the Kyoto agreement: results from the MS-MRT model
}

\author{
Paul M. Bernstein a, W. David Montgomery ${ }^{\mathrm{a}, *}$, \\ Thomas F. Rutherford ${ }^{b}$ \\ ${ }^{a}$ Charles River Associates, 600 13th Street NW, Washington DC 20005, USA \\ ${ }^{\mathrm{b}}$ University of Colorado, USA
}

Received 15 August 1998; received in revised form 15 January 1999; accepted 20 January 1999

\begin{abstract}
This paper analyzes the economic impacts on different regions of the world of a global agreement to limit carbon emissions. A multi-sector, multi-region trade model (MS-MRT) is developed that focuses on the international trade aspects of climate change policy. These include the distribution of impacts on economic welfare, international trade and investment across regions, the spillover effects of carbon emission limits in Annex 1 countries on non-Annex 1 countries, carbon leakage, changes in terms of trade and industry output, and the effects of international emissions trading. Our central estimates are presented with a set of sensitivity tests to assess the extent to which our conclusions depend on elasticity and baseline assumptions. A technical appendix presents algebraic details of the model structure and calibration. (C) 1999 Elsevier Science B.V. All rights reserved.
\end{abstract}

Keywords: Climate; International trade; Emissions trading; General equilibrium models

\section{Overview}

International negotiations over a global policy to address climate change have been underway for many years. These negotiations led first to the adoption in 1992

\footnotetext{
* Corresponding author. Tel.: + 1-202-662-3840; Fax: +1-202-662-3910; E-mail: wdm@crai.com 
of the United Nations Framework Convention on Climate Change (FCCC), signed by 154 nations at the Rio Earth Summit. The first session of the Conference of the Parties (COP-1) ${ }^{1}$ in Berlin in 1995 followed this agreement. Two years later, in December 1997, the third Conference of the Parties (COP-3) convened in Kyoto, where representatives from over 150 countries produced an agreement known as the Kyoto Protocol.

This agreement defined the next steps to be taken to reduce emissions and identified a series of important issues about the future course of climate change policy. The Protocol calls for the majority of industrialized countries to limit their emissions of greenhouse gases by the first part of the next century and includes several 'flexibility mechanisms,' such as the international trading of emission permits, that could significantly reduce costs for some countries.

Industrial countries agreed to limit their greenhouse gas emissions, averaged over the 5-year period from 2008-2012, to specific percentages of their 1990 or 1995 emissions. The percentages range from 92\% - for the European Union and some other countries - to $108 \%$ for Australia. Developing countries undertook no commitments to limit their emissions and insisted on deleting from the Protocol any proposed procedures under which such commitments could be made. Flexibility mechanisms included coverage of six greenhouse gases, provisions for international emissions trading, credits for reforestation and other actions that remove greenhouse gases from the atmosphere ('sinks'), and a Clean Development Mechanism under which industrial countries could finance and gain credit for emission reductions in developing countries.

Virtually all of the details of the flexibility mechanisms remain open for further negotiation. These include such issues as the role of developing countries in the overall emissions reduction effort and the scope and design of international emission trading. International trade is a common theme in many of the issues and questions that were important in the negotiations leading up to Kyoto and that remain open after Kyoto. These include:

- Distribution of economic impacts across regions:

- How will developing countries be affected by emission limits adopted in the industrial countries?

- How will the costs of reducing emissions be distributed among countries that do agree to emission limits?

- Carbon leakage and effects on international competition:

- How will investment and output in energy-intensive industries be affected when some countries agree to binding emission limits and others do not?

- How large will leakage of carbon emissions from participating to non-participating countries be?

\footnotetext{
${ }^{1}$ The COP is the supreme body of the Convention. It was established to meet once a year to review the Convention's progress.
} 
- Effects of international emission permit trading:

- How will emission limits and international permit trading affect the terms of trade and capital flows between countries?

- Who will be the buyers and sellers of permits in an international permit trading system?

- Will developing countries be made better or worse off by participating in a system of international permit trading?

The first set of questions, about the impacts of Annex 1 country actions on non-Annex 1 countries, was highlighted in the Kyoto negotiations and has been set as a specific subject for inquiry by the Intergovernmental Panel on Climate Change. Questions about 'industrial competitiveness' have been an important part of the debate in almost all Annex 1 countries, with varying degrees of understanding of the economic issues involved. How an international emission trading system will work is central to the current negotiations for implementing the Kyoto agreement. In particular, the question of whether and to what extent international emissions trading will alter the distribution of costs among countries, and whether trading will ameliorate what are seen as competitive effects, may be crucial in the ratification and implementation of the treaty in industrial countries.

The focus of this paper is on the policy insights of a large-scale modeling exercise. As such, the body of the paper focuses primarily on features of the model and the results. Our central estimates are presented with a substantial set of sensitivity tests to assess the extent to which our conclusions depend on elasticity and baseline assumptions. We hope that the exposition will be sufficiently intuitive that a reader will conclude that 'most of the qualitative impacts could have been gauged without a compatable general equilibrium (CGE) model'. This provides a useful starting point for sensitivity analyzes in which we can quantify the extent to which these results are dependent on particular assumptions.

The remainder of this paper includes three sections. Section 2 describes in words how we have modeled the economic effects of the Kyoto Protocol. Section 3 presents the model results and sensitivity analyses. Section 4 is a brief concluding section and is followed by Appendices $\mathrm{A}$ and $\mathrm{B}$, which present algebraic details of the model structure and calibration.

\section{Modeling the Kyoto Protocol}

We have developed a multi-sector, multi-region trade (MS-MRT) model to help us understand the international trade aspects of climate change policy. These include the distribution of impacts across countries: the spillover effects of carbon emission limits in Annex 1 countries on non-Annex 1 countries, carbon leakage, changes in terms of trade and industry output, and the effects of international emission trading. 
Conceptually, the model is a conventional neoclassical general equilibrium model based on relative prices, optimizing behavior, and in which there is no monetary sector. The global economy is represented by regions, and consumption and savings within each region are characterized by a representative agent. Goods are indexed by region and time. All markets clear simultaneously, so that agents anticipate future changes in terms of trade and take these into account in saving and investment decisions. Even though there is no money in the model, changes in the prices of internationally traded goods, capital flows, and sales of permits produce changes in the real terms of trade between regions.

Each region's budget constraint implies that there can be no change in any region's net foreign indebtedness over the time horizon of the model. In any given period, a country can be a net borrower or lender, running a trade deficit or surplus, but by the terminal year debt must be returned to baseline levels. In an infinite horizon model, this closure rule follows naturally from the budget constraint and serves to rule out the possibility of an infinite accumulation of debt-in effect, a 'no-Ponzi-scheme' condition. Our condition that there be no net change in foreign indebtedness over a finite horizon is approximation of this infinite horizon condition ${ }^{2}$. We also include a terminal condition through a constraint that forces the agent to purchase enough capital to make investment grow smoothly in the last period, so that consequences of decisions taken during the time horizon on future welfare are accounted for (Rutherford, 1998a).

The dynamic general equilibrium framework was chosen for several reasons. The first is that an Arrow-Debreu model with complete and efficient markets over space and time focuses on how emission limits affect the efficiency of resource allocation. A theoretically satisfactory measure of welfare can be taken directly from the model. Foresight and complete markets make it impossible for modelers acting as policy makers to improve the welfare of agents in the models by exploiting knowledge of model outcomes in future periods denied to the agents.

The model includes a disaggregated representation of industries, based on the Global Trade Analysis Project (GTAP) data set (Hertel, 1997), so that differences in energy intensities across countries and differences in the composition of industries can be taken into account. MS-MRT can represent a wide variety of international emission trading regimes, including a capability of defining trading blocs composed of any grouping of regions and constraints on both purchases and sales of emission permits.

\footnotetext{
${ }^{2}$ It is also possible to implement a no-Ponzi-scheme condition by putting a bound on debt accumulation, and adding a lump-sum transfer to account for the required repayment beyond the time horizon. This approach would allow for debt accumulation over the time horizon, as in G-CUBED, while still preserving the utility-maximization framework. A simple version of such a model was created, and sensitivity analysis revealed no significant changes in welfare or GDP impacts between cases with zero change in indebtedness and a finite change in indebtedness accompanied by a lump-sum transfer.
} 
The MS-MRT model follows Armington (1969) in its representation of international trade in all goods except crude oil. The model places no constraints on borrowing or lending by individual producers or consumers. Crude oil is treated as a homogeneous good perfectly substitutable across regions. In order to capture some of the short run costs of adjustment, elasticities of substitution between different fuels and between energy and other goods vary with time. Physical capital is malleable but cannot be transferred across sectors. The model is benchmarked to assumed baseline rates of economic growth and a common 5\% net rate of return on capital in all countries. The rate of growth in the effective labor force (population growth plus labor-augmenting technical progress) and the consumption discount rate are computed so that the model produces a dynamic market equilibrium consistent with the assumed rates of growth and return on capital.

The MS-MRT model divides the world into 10 geopolitical regions. These 10 regions represent a compromise between a desire for greater detail to mirror the diversity of the world's economies and the different carbon limits assigned under the Kyoto Protocol, and practical limitations of solution time and on data requirements. The Kyoto Protocol treats Annex 1 countries differently from Non-Annex 1 countries, and these proposals apply differentiated targets within the Annex 1 countries. The Annex 1 countries must limit their emissions whereas Non-Annex 1 countries face no restrictions. Within Annex 1, the OECD economies are vastly different from those of Eastern Europe and the Former Soviet Union (EE/FSU). The EE/FSU countries are assigned emissions limits much less binding than those on the OECD. Furthermore, member states of the European Union may find their targets require smaller reductions from baseline than other regions. Japan and Canada face different circumstances and costs than other OECD regions, while the other OECD countries contain a major coal exporter, Australia. Some of these regions may trade emissions with each other, and some may not.

In order to facilitate examination of emission trading among different groups of countries, Annex 1 is divided into the following five regions: the European Union of 15 countries (EU15), Eastern Europe and the Former Soviet Union (EE/FSU), Japan, the United States, and other OECD (OOE). Within the Non-Annex 1 countries, there are large differences between energy exporters, such as OPEC countries, and energy importers, such as South Korea. Because of the special situation of Asian economies, we divide the energy-importing non-Annex 1 countries into four groups: Southeast Asia including Korea (SEA), China and India (CHI), other Asia (OAS), and Rest of World (ROW), which mainly includes Central and South America and sub-Saharan Africa. Mexico and OPEC (MPC) is the last of the 10 regions.

The MS-MRT model is calibrated to the benchmark year 1995. Then, it solves in 5-year intervals spanning the horizon from 2000 to 2030; the year 2000 is the first endogenous year. 
Nine industries are represented in the MS-MRT model structure:

- Five forms of energy: crude oil, refined products, coal, natural gas, and electricity;

- Four non-energy goods: agriculture, chemicals, other energy-intensive sectors, and all other goods.

Each of these industries can produce goods for domestic consumption or for export. In the case of non-energy goods, we assume that domestically produced goods and imports from each region are differentiated products. Domestic goods and imports are combined into Armington aggregates, which then are inputs into production or consumption.

The model includes the markets for the three fossil fuels. Electricity is produced using these fuels, capital, labor, and materials as inputs. Crude oil trades internationally under a single world price. Natural gas and coal are represented as Armington goods, to approximate the effects of infrastructure requirements and high transportation costs between some regions. Depletion is assumed to lead to rising fossil fuel prices under constant demand, but the relation between depletion effects on the supply of oil, gas, and coal and the actual supply of these fuels is ignored. That is, the model does not keep a record of the current stock of each fuel in each time period. World supply and demand determine the world price of fossil fuels. Current energy taxes and subsidies are included in each country's energy prices (except for EE/FSU). We assume that by $2005 \mathrm{EE} / \mathrm{FSU}$ will move to market based pricing, removing the extraordinary taxes and subsidies implicit in 1995 data. The carbon-free backstop, represented as a carbon sequestration activity that requires inputs of non-energy goods, establishes an upper bound on world fossil fuel prices.

The model is benchmarked to the GTAP-IEA data set, which provides prices and a social accounting matrix for each region and bilateral trade flows by industry between all regions. The GTAP data provide information on industry structure and energy intensity of exports and imports necessary to assess impact on competitiveness. They reveal wide differences in energy intensity for the same industry in different regions.

Table 1 compares differences in energy intensity of various products across regions in the base year (1995) data. These data were developed by combining the GTAP-4 economic data with IEA data on energy prices and quantities for the regions included in the GTAP database (see Babiker et al., 1997).

The economic data originally in the GTAP dataset were found to present an inconsistent picture of energy prices and quantities when compared with reliable data on energy sectors developed by the IEA. Therefore, we used the IEA data to correct the GTAP value data on energy in order to have a consistent dataset, in which values in GTAP corresponded to the product of IEA energy prices and quantities.

The energy value shares implied by these corrected data differ dramatically across countries. In addition, the IEA data reveal large differences in energy prices 
Table 1

Carbon intensity of sectoral output ( $\mathrm{kg}$ per US\$ of output)

\begin{tabular}{llllll}
\hline Region & Electricity & Energy intensive & Chemicals & Agriculture & All other goods \\
\hline USA & 2.53 & 0.27 & 0.32 & 0.45 & 0.06 \\
JPN & 0.48 & 0.09 & 0.08 & 0.04 & 0.02 \\
EUR & 1.14 & 0.13 & 0.14 & 0.07 & 0.03 \\
OOE & 1.24 & 0.22 & 0.21 & 0.09 & 0.05 \\
SEA & 1.61 & 0.20 & 0.26 & 0.07 & 0.06 \\
OAS & 1.25 & 0.28 & 0.29 & 0.06 & 0.06 \\
CHI & 7.20 & 1.17 & 1.01 & 0.19 & 0.21 \\
FSU & 7.76 & 1.29 & 1.03 & 0.86 & 0.28 \\
MPC & 3.41 & 0.43 & 0.43 & 0.18 & 0.14 \\
ROW & 1.28 & 0.27 & 0.16 & 0.07 & 0.07 \\
\hline
\end{tabular}

and in implicit taxes and subsidies across countries. For example, in the case of chemicals, developing countries are seen to use over 10 times as much carbon as industrial countries per dollar of industrial output. It is not surprising that under global trade, output of chemicals in developing countries falls relative to the baseline, as equal permit prices across all regions shift the comparative advantage in chemicals production toward industrial countries.

\section{Impacts of the Kyoto Protocol}

For this paper, the MS-MRT was run under three international trading regimes: no trading, trading only among Annex 1 countries, and full global trading. No restrictions on sales or purchases of emission permits were assumed. These restrictions, which are under active negotiation, are treated in a related paper (Bernstein et al., 1999). Each Annex 1 region was assigned emission limits for 2010 consistent with its obligation under the Kyoto agreement (see Table 2).

The MS-MRT is benchmarked to the reference forecast of carbon emissions developed by the US Energy Information Administration. This forecast suggests

Table 2

Carbon emissions targets for 2010 in Annex 1 countries

\begin{tabular}{lllc}
\hline Region & $\begin{array}{l}\text { Reduction target } \\
\text { from 1990 }(\%)\end{array}$ & $\begin{array}{l}\text { Reduction target } \\
\text { from 2010 (BAU) }(\%)\end{array}$ & $\begin{array}{l}\text { BAU emissions growth } \\
(1990 \text { to 2010) }(\%)\end{array}$ \\
\hline US & -7 & -30 & 34 \\
Japan & -6 & -24 & 24 \\
EU15 & -8 & -18 & 12 \\
Other OECD & 1 & -25 & 31 \\
EE/FSU & 0 & 20 & -18 \\
\hline
\end{tabular}


considerable disparity in emissions growth across the Annex 1 region. Table 2 provides three statistics on the baseline emissions growth through 2010 for each region: its projected growth in emissions for 1990-2010, its target for emissions as a percentage of 1990 emissions, and the required reductions in emissions. Russia has a target higher than its projected emissions, so it need take no action through 2010. The EU has a proportionally smaller required reduction than the US.

\subsection{Carbon permit prices}

We assume that the Kyoto Protocol is implemented in each Annex 1 region by means of a domestic emission cap and trading program that establishes a single price for carbon within each region (and achieves required emission reductions at minimum cost). When there is no international emission trading, permit prices will differ across countries indicating which countries have more or less difficulty meeting their targets and also identifying potential gains from trade. With no international permit trade, permit prices are highest in Japan and lowest in Russia. The US is in the middle. As discussed above, the baseline forecast is benchmarked to the current forecast of the Energy Information Administration, which projects that in 2010 Russia's emissions will be well below its target of $100 \%$ of 1990 emissions. Since Russia will not need to take any additional actions to limit emissions, its carbon permit price is zero until after 2010. All Annex 1 countries are assumed to have the same end-use elasticities.

Differences in permit prices across OECD regions in the no-trade case are likely to be due to differences in one of four factors: pre-existing energy prices, the share of coal in total energy use, the amount of energy produced domestically, and the required reduction in emissions given the Kyoto target and baseline emissions growth. All else being equal, permit prices will be proportional to baseline energy prices. With identical demand elasticities (elasticities of substitution between energy and the value-added aggregate-esub, and between different forms of energy-isub) and coal shares across countries, two countries with identical required reductions in emissions will have different carbon permit prices if their baseline energy prices differ.

The GTAP data reveal large differences in energy taxes, subsidies, and prices across countries, and therefore, leads to the expectation that permit prices will differ. Since coal has a higher carbon intensity than other fuels, coal prices (inclusive of permit costs) rise more than the price of any other fuel. Therefore, differences in coal shares will also lead to differences in permit prices. Countries with larger coal shares also have an option for reducing emissions, interfuel substitution, that is denied to countries with smaller coal shares.

Domestic energy production has a surprisingly large effect on the required carbon tax, particularly for coal which is differentiated by region of origin. If a 
country is entirely dependent on imported energy, the producer price of fuels will be largely independent of the permit price in that country, being determined by world market conditions. If a country is largely self-sufficient, the producer price of fuels will be driven down by reduced demand. The permit price will have to be higher than in a country where producer prices for energy are determined by world markets.

Finally, differences in baseline emissions growth and targets can lead to differences in required emission reductions across countries that will also require different permit prices, all else equal.

In the MS-MRT results, differences in permit prices are due to all four factors. Countries do differ in required reductions, with the EU having the smallest required reduction and the US the largest (Table 2). This leads to the expectation that the US carbon price should exceed that in the EU. On the other hand, Europe has much higher pre-existing energy prices than the US, and a somewhat smaller coal share (Table 3), leading to the expectation that the EU permit price should exceed that of the US.

In the No Trade case under Kyoto limits, the 2010 permit price in Japan is 2.5 times as large as the price in the EU, and the permit price in the US is slightly higher than that in the EU. A sensitivity analysis in which we equalize the required reduction in emissions across regions illustrates the different factors at work in determining these permit prices (Table 4). Under the Kyoto Limits, the percentage change in non-electric energy prices also varies significantly across regions, with the US having the largest percentage change, twice that in Europe, which has the smallest. This difference is due to the combined effect of targets, pre-existing prices, and energy mix. When identical emission reductions are assumed, the range is narrowed considerably, with the US having the highest aggregate energy price increase, followed by Japan, OOE, and the EU. Looking at price increases for individual fuels in the equal reduction case shows how the energy mix affects

Table 3

Fossil fuel shares

\begin{tabular}{llll}
\hline & Coal & Oil & Gas \\
\hline USA & 0.21 & 0.25 & 0.19 \\
JPN & 0.14 & 0.38 & 0.08 \\
EUR & 0.16 & 0.31 & 0.13 \\
OOE & 0.16 & 0.28 & 0.19 \\
SEA & 0.12 & 0.36 & 0.07 \\
OAS & 0.12 & 0.44 & 0.19 \\
CHI & 0.63 & 0.16 & 0.03 \\
FSU & 0.23 & 0.18 & 0.35 \\
MPC & 0.02 & 0.29 & 0.20 \\
ROW & 0.18 & 0.30 & 0.11 \\
\hline
\end{tabular}


Table 4

Sensitivity analysis of emissions targets

\begin{tabular}{|c|c|c|c|c|c|c|}
\hline & \multicolumn{2}{|l|}{ Gas } & \multicolumn{2}{|l|}{ Oil } & \multicolumn{2}{|l|}{ Coal } \\
\hline & Demand & Price & Demand & Price & Demand & Price \\
\hline \multicolumn{7}{|c|}{ Uniform reduction in carbon emissions across regions (\% change in 2010$)$} \\
\hline USA & -25 & 146 & -15 & 95 & -45 & 381 \\
\hline JPN & -49 & 266 & -9 & 78 & -64 & 703 \\
\hline EUR & -38 & 177 & -9 & 49 & -57 & 530 \\
\hline OOE & -41 & 186 & -9 & 61 & -49 & 509 \\
\hline \multicolumn{7}{|c|}{ Percentage change in nonelectric energy price (\% change in 2010 ) } \\
\hline & USA & JPN & EUR & OOE & & \\
\hline Non-uniform reduction & 151 & 96 & 74 & 75 & & \\
\hline Uniform reduction targets & 153 & 132 & 102 & 127 & & \\
\hline
\end{tabular}

the permit price required to achieve equal emission reductions. For each fuel, percentage reductions in demand are proportional to percentage increases in prices. These are the results to be expected when the same demand elasticity is used in each country. The aggregate US price increase exceeds that for other countries because the US has the largest coal share in consumption, and coal prices rise more than other fuel prices in proportional terms. An additional sensitivity analysis in which we varied isub had no effect on permit prices, indicating that opportunities for interfuel substitution with this dataset and model are not as important in explaining intercountry differences in permit prices.

Trade among Annex 1 countries creates a uniform permit price in those countries of about US $\$ 89$ per metric ton in 2010 , and global trade establishes a global uniform permit price of about US $\$ 30$ per metric ton in 2010 (see Table 5). The additional supply of permits from non-Annex 1 countries drives down permit prices.

Table 6 presents an analysis of permit prices for alternative baseline emissions paths and alternative elasticities of energy demand. We find that the primary determinant of carbon tax rates is the assumed baseline emissions trajectory. In the alternative case, we give each region identical percentage emission reduction requirements, by rebenchmarking the model so that carbon emissions in each region grow at the same rate as the US, and assign each Annex 1 region an emission limit of $93 \%$ of 1990 emissions. This case serves to remove the influence of differing targets, and shows much closer permit prices than the reference case.

\subsection{Permit sales and purchases}

Under Annex 1 trading, Russia will be the only seller of permits because of its advantageous position caused by the large positive difference between its target 
Table 5

Carbon permit trade

\begin{tabular}{|c|c|c|c|c|c|c|c|}
\hline & \multicolumn{3}{|c|}{$\begin{array}{l}\text { Permit price } \\
\text { (1995 US\$/metric ton) }\end{array}$} & \multicolumn{2}{|c|}{$\begin{array}{l}\text { Permit purchases } \\
\text { (millions of metric tons of carbon) }\end{array}$} & \multicolumn{2}{|c|}{$\begin{array}{l}\text { Permit purchases } \\
\text { (billions of } 1995 \text { dollars) }\end{array}$} \\
\hline & $\overline{\mathrm{NT}}$ & A1 & $\overline{G L}$ & $\overline{\mathrm{A} 1}$ & GL & $\overline{\mathrm{A} 1}$ & GL \\
\hline \multicolumn{8}{|l|}{2010} \\
\hline USA & 274 & 89 & 30 & 305.0 & 461.8 & 27.3 & 13.9 \\
\hline JPN & 482 & 89 & 30 & 57.4 & 81.1 & 5.1 & 2.4 \\
\hline EUR & 211 & 89 & 30 & 103.5 & 165.1 & 9.2 & 5.0 \\
\hline OOE & 246 & 89 & 30 & 40.1 & 61.9 & 3.6 & 1.9 \\
\hline SEA & 0 & 0 & 30 & 0.0 & -49.0 & NA & -1.5 \\
\hline OAS & 0 & 0 & 30 & 0.0 & -12.0 & NA & -0.4 \\
\hline $\mathrm{CHI}$ & 0 & 0 & 30 & 0.0 & -247.6 & NA & -7.5 \\
\hline FSU & 0 & 89 & 30 & -506.0 & -311.8 & -45.2 & -9.4 \\
\hline MPC & 0 & 0 & 30 & 0.0 & -58.3 & NA & -1.8 \\
\hline ROW & 0 & 0 & 30 & 0.0 & -91.3 & NA & -2.8 \\
\hline \multicolumn{8}{|l|}{2030} \\
\hline USA & 353 & 224 & 32 & 180.4 & 709.4 & 40.4 & 22.5 \\
\hline JPN & 526 & 224 & 32 & 108.5 & 183.9 & 24.3 & 5.8 \\
\hline EUR & 431 & 224 & 32 & 184.8 & 429.0 & 41.4 & 13.6 \\
\hline OOE & 505 & 224 & 32 & 59.1 & 141.2 & 13.3 & 4.5 \\
\hline SEA & 0 & 0 & 32 & 0.0 & -123.3 & NA & -3.9 \\
\hline OAS & 0 & 0 & 32 & 0.0 & -37.6 & NA & -1.2 \\
\hline $\mathrm{CHI}$ & 0 & 0 & 32 & 0.0 & -901.3 & NA & -28.6 \\
\hline FSU & 50 & 224 & 32 & -532.8 & -6.1 & -119.5 & -0.2 \\
\hline MPC & 0 & 0 & 32 & 0.0 & -153.8 & NA & -4.9 \\
\hline ROW & 0 & 0 & 32 & 0.0 & -241.4 & NA & -7.7 \\
\hline
\end{tabular}


Table 6

Sensitivity analyses for carbon tax rates

\begin{tabular}{lccc}
\hline & Low & Reference & High \\
\hline Baseline emissions path (1995 US\$ $/$ metric ton in 2010) & & \\
USA & 206 & 274 & 338 \\
JPN & 218 & 482 & 513 \\
EUR & 105 & 211 & 351 \\
OOE & 146 & 247 & 363 \\
Global Carbon Emissions in 2020 & 8.2 & 10.3 & 12.3 \\
(Billions of metric tons) & & \\
& & \\
Elasticity of energy demand (1995 US\$/metric ton in 2030) & \\
\hline \multicolumn{5}{c}{ Short-0.35, Long-0.6 } \\
USA & Short-0.5, Long-1.0 \\
JPN & 352 & 237 \\
EUR & 526 & 526 \\
OOE & 449 & 329 \\
\end{tabular}

and baseline emissions. The United States will purchase about half the permits sold by Russia, followed by the EU and Japan. With global trading, about 200 million tons of Russian permit sales are displaced by sales from other countries. In the Annex 1 trading case, Russia would receive payments for its permit sales of about US $\$ 45$ billion in 2010, over half coming from the United States. Under global emission trading, Russia's revenues would fall to about US\$9 billion in 2010 (see Table 5).

\subsection{Energy prices}

Unless there is global emissions trading, energy prices will be driven up in Annex 1 countries and down in non-Annex 1 countries because of the differences in obligations under the Kyoto Protocol. The price of carbon permits will be incorporated in the prices of fossil fuels in Annex 1 countries, leading to price increases relative to baseline. Non-Annex 1 countries will face slightly lower prices. The reduction in demand due to emission limits in industrial countries will cause market prices for all traded forms of energy to fall, to the benefit of oil and other energy-importing developing countries. The spread is largest with no trading, and it is narrowed with Annex 1 trading (see Table 7).

These disparities in energy prices cause shifts in investment and output from energy-intensive industries, as well as changes in the terms of trade that transfer income across countries. With global trading, permit prices are the same in all countries, and energy prices rise in Annex 1 and non-Annex 1 countries. 
Table 7

Energy prices at the industry level (\% change from baseline)

\begin{tabular}{|c|c|c|c|c|c|c|}
\hline & \multicolumn{2}{|l|}{ NT } & \multicolumn{2}{|l|}{ A1 } & \multicolumn{2}{|l|}{ GL } \\
\hline & 2010 & 2030 & 2010 & 2030 & 2010 & 2030 \\
\hline USA & 175.2 & 198.9 & 53.1 & 123.8 & 16.0 & 15.5 \\
\hline JPN & 114.0 & 115.6 & 22.8 & 51.2 & 6.7 & 6.6 \\
\hline EUR & 51.9 & 107.0 & 19.0 & 45.4 & 4.9 & 5.0 \\
\hline OOE & 98.7 & 177.7 & 31.5 & 71.5 & 8.6 & 8.3 \\
\hline SEA & -9.1 & -11.8 & -7.2 & -12.4 & 10.3 & 10.4 \\
\hline OAS & -4.9 & -6.2 & -2.9 & -6.0 & 11.3 & 11.3 \\
\hline CHI & -2.4 & -3.9 & -1.9 & -4.0 & 25.3 & 29.3 \\
\hline FSU & -8.0 & 10.9 & 51.1 & 111.0 & 14.3 & 13.1 \\
\hline MPC & -7.2 & -11.1 & -7.2 & -12.3 & 12.0 & 11.8 \\
\hline ROW & -8.8 & -8.8 & -7.2 & -9.6 & 12.5 & 13.1 \\
\hline
\end{tabular}

\subsection{Welfare impacts under alternative trading arrangements}

We use Hicksian equivalent variation in income over an infinite horizon to provide a concise metric of welfare impacts. The model only runs through 2030, but we may use terminal period consumption to infer infinite-horizon welfare, assuming no change in post-terminal growth rates. A welfare impact then is expressed as the equivalent percentage change in infinite-horizon income at baseline prices.

Welfare impacts for alternative baseline emission paths and elasticities of energy demand and trade are presented in Table 8. In brief, the MS-MRT model consistently finds that emission limits on industrial countries with no international emissions trading have uniformly negative impacts on the welfare of Annex 1 countries and oil producing countries, and mixed impacts on other non-Annex 1 countries. Emission limits in the industrial countries benefit only China and India (CHI) and harm the rest of the non-Annex 1 countries (see Fig. 1).

Annex 1 trading improves the situation relative to no trading for all regions except China and India. Russia benefits from its large sales of emission permits to other Annex 1 regions. Russia's terms of trade improve under Annex 1 trading despite its permit revenues. Prices of Armington imports also rise because of the inflow of income from permit sales, but this change is offset by an increase in the price of Armington exports. Costs of production rise in EE/FSU, because of the opportunity cost of selling permits, leading to an increase in the price of EE/FSU exports in an Armington world. At the same time, the volume of exports declines dramatically and the volume of imports increases. In this sense, Russia contracts the 'Dutch Disease' of declining exports and a reduction in industrial investment and output because of its ability to live on the proceeds of permit sales.

Global trading is worse for China and India than no trading, because it removes pecuniary externalities that benefited those regions under limited emission trading. When global trading reduces permit prices, Russia loses most of the welfare gain 
Table 8

Hicksian equivalent variation in income (\% of present value consumption)

\begin{tabular}{|c|c|c|c|}
\hline & Low & Reference & High \\
\hline \multicolumn{4}{|l|}{ Baseline emissions scenarios } \\
\hline USA & -0.26 & -0.54 & -0.90 \\
\hline JPN & -0.26 & -0.68 & -1.08 \\
\hline EUR & -0.12 & -0.43 & -0.98 \\
\hline OOE & -0.40 & -0.97 & -1.81 \\
\hline SEA & -0.13 & -0.18 & -0.14 \\
\hline OAS & -0.07 & -0.11 & -0.03 \\
\hline $\mathrm{CHI}$ & 0.19 & 0.40 & 0.68 \\
\hline FSU & -0.25 & -0.37 & -1.39 \\
\hline MPC & -0.71 & -1.35 & -2.02 \\
\hline ROW & -0.02 & -0.09 & -0.09 \\
\hline Global carbon emissions in 2020 (Billions of metric tons) & 8.24 & 10.33 & 12.28 \\
\hline \multicolumn{4}{|l|}{ Sensitivity to elasticity of substitution } \\
\hline & $\begin{array}{l}\text { Short }-0.35 \text {, } \\
\text { Long }-0.6\end{array}$ & $\begin{array}{l}\text { Short }-0.5, \\
\text { Long }-1.0\end{array}$ & \\
\hline$\overline{\mathrm{USA}}$ & -0.54 & -0.40 & \\
\hline JPN & -0.68 & -0.62 & \\
\hline EUR & -0.43 & -0.42 & \\
\hline OOE & -0.97 & -0.93 & \\
\hline SEA & -0.18 & -0.06 & \\
\hline OAS & -0.11 & 0.01 & \\
\hline $\mathrm{CHI}$ & 0.40 & 0.42 & \\
\hline FSU & -0.37 & -0.36 & \\
\hline MPC & -1.35 & -1.52 & \\
\hline ROW & -0.09 & -0.09 & \\
\hline
\end{tabular}

Sensitivity to Armington elasticities

\begin{tabular}{lcc}
\hline & $\mathrm{dm}-1, \mathrm{~mm}-2$ & $\mathrm{dm}-4, \mathrm{~mm}-8$ \\
\hline USA & -0.46 & -0.54 \\
JPN & -0.51 & -0.68 \\
EUR & -0.41 & -0.43 \\
OOE & -1.43 & -0.97 \\
SEA & -0.21 & -0.18 \\
OAS & 0.00 & -0.11 \\
CHI & 0.32 & 0.40 \\
FSU & -0.68 & -0.37 \\
MPC & -2.48 & -1.35 \\
ROW & -0.30 & -0.09 \\
\hline
\end{tabular}

from permit sales provided by Annex 1 trading. Non-Annex 1 regions other than China and India benefit from improved demand for exports and lower import prices due to improved economic conditions in Annex 1, as well as permit sales. 


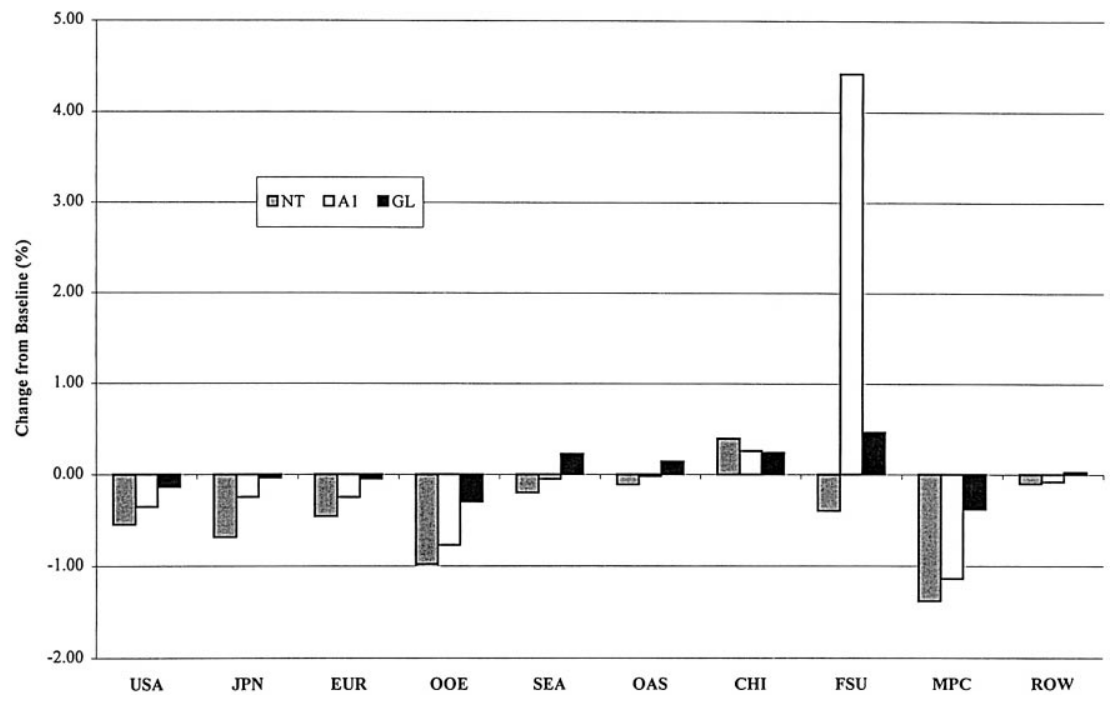

Fig. 1. Welfare impacts of Kyoto Protocol.

We have performed a number of sensitivity analyses of the welfare impacts: (1) The principal determinant of the welfare cost is the baseline emissions growth. ${ }^{3}$ Comparing the IEO reference and high baseline growth paths, we find increases in welfare costs of as much as 50\%. (2) The energy demand substitution parameter produces relatively small changes in welfare loss, even with long-term values as high as unity. (3) Armington elasticities produce small changes in welfare for OECD countries but can alter welfare for Russia and the non-Annex 1 countries. For example, when the trade elasticities are doubled, the welfare cost for the oil exporting countries decreases from $2.5 \%$ to $1.5 \%$. Qualitatively the welfare results are essentially unchanged.

The negative impacts on some developing countries are particularly interesting because those countries are under no obligation to take any action to reduce their emissions. For any given country in any given year, the impacts of the Kyoto Protocol will be the result of the direct cost of actions taken to reduce emissions, changes in investment due to anticipation of future costs, changes in terms of trade (including energy and non-energy goods), and payments for permits. With no international emission trading, developing countries will only be affected by changes in terms of trade and changes in investment. Therefore, it is to these two impacts that we must look for an explanation of why developing countries can lose when industrial countries limit their emissions.

\footnotetext{
${ }^{3}$ The high, reference, and low emissions cases are generated by benchmarking to the corresponding cases in the EIA 1998 International Energy Outlook (IEO).
} 


\subsection{Terms of trade changes}

Terms of trade generally move against developing countries and in favor of industrial countries when developing countries do not participate in international emissions trading (see Fig. 2). Looking at terms of trade from the point of view of a non-Annex 1 country, there are three potentially offsetting effects when there is no global emissions trading.
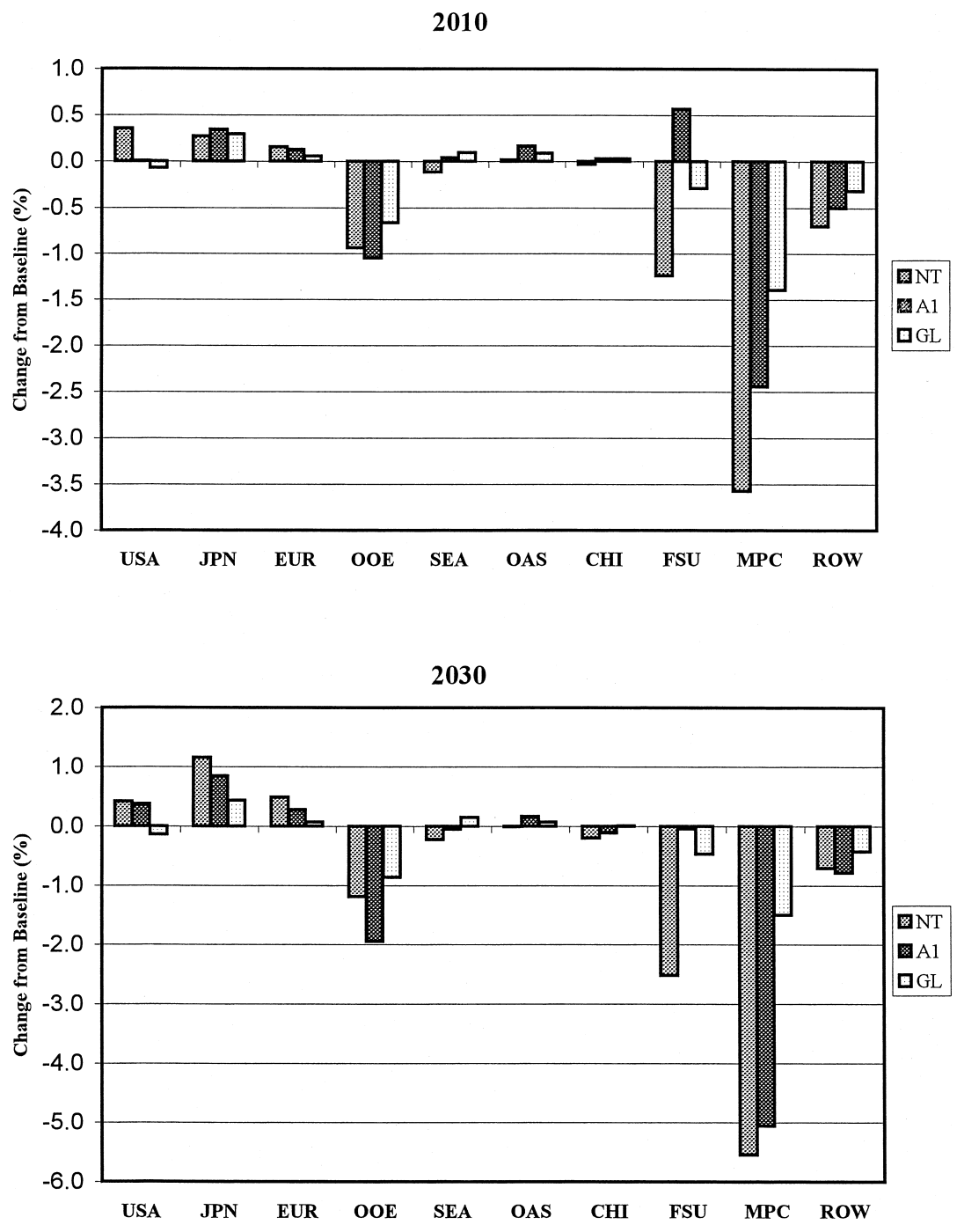

Fig. 2. Terms of trade (price of exports/price of imports). 
(1) Non-Annex 1 countries will pay higher prices for imports from Annex 1 countries. The costs of industrial countries' exports increase because of higher energy prices.

(2) An income effect will depress industrial countries, demand for exports from non-Annex 1 countries as industrial countries' incomes fall. This effect will tend to drive down the price of imports from developing countries. The price paid in Annex 1 countries for oil exports from non-Annex 1 countries will also fall, because emission limits will drive down the producer price of oil in the Annex 1 countries.

(3) A substitution effect will tend to increase demand for energy-intensive goods produced in developing countries because of the higher producer price of these goods in Annex 1 countries.

Whether terms of trade improve or deteriorate for a given country or region depends on which of these three effects dominates. These changes in the terms of trade are the reason for the negative GDP and welfare impacts on developing countries noted above. These changes are most obvious for the oil exporting countries. Demand for oil and world oil prices are unambiguously reduced by emission limits, so that revenues received from the export of this good fall.

Furthermore, goods imported from the industrial countries rise in cost, placing energy exporters in a terms of trade squeeze.

Oil importing developing countries face potentially offsetting effects. Some oil importing countries will face a deterioration in their terms of trade with industrial countries that is small enough to be offset by an improvement in their terms of trade with oil exporting countries. Other Asian countries (OAS) more than offset the higher cost of imports from industrial countries with gains in terms of trade with OPEC and the ability to shift to production of energy-intensive goods where they have an increased comparative advantage over the industrial countries. These countries also benefit from capital inflows and from their favorable position as exporters of energy-intensive goods in the baseline. Under the Armington specification, the percentage increase in imports by any region is tied to the percentage change in the relative price of imports. If imports from some regions are very small, it takes a very large change in relative prices to cause a significant change in quantity. Therefore, it is necessary to be an exporter in the baseline to be able to increase exports significantly in the carbon limit case. Annex 1 countries also benefit from the reduction in world oil prices, since they are clearly able to shift some of the cost of complying with emission limits onto the oil exporting countries in the form of lower prices for oil.

Another way of interpreting these results is to think of the industrial countries as producers of goods sold to developing countries and buyers of goods from developing countries who are subject to excise taxes. Then the question of what will happen to developing countries becomes a standard problem of tax incidence: given supply and demand elasticities, how much of a tax levied on one party to a transaction will be shifted to another party? It is not surprising, in this view, that 
some of the costs of carbon limits in the Annex 1 countries are shifted onto the non-Annex 1 countries. Indeed, any other result would be surprising in light of the general phenomenon of tax shifting.

Annex 1 trading produces smaller changes in terms of trade, with some developing countries showing losses relative to Annex 1 countries, and some gains. With global trading, terms of trade improve for a number of developing countries relative to the Annex 1 countries because of their permit sales (see Fig. 2).

Terms of trade always move in a direction that appears favorable to sellers of permits. Russia's terms of trade improve in Annex 1 trading. This is because of the much higher costs Russia incurs with a positive, rather than zero, permit price. To maintain the balance of payments equilibrium, Russia's net imports must increase to balance the revenues from permit sales. The price of exports must rise relative to the price of imports to eliminate that deficit.

\subsection{Changes in aggregate investment}

With no trading or Annex 1 trading, investment rises in non-Annex 1 countries and falls in Annex 1 countries (see Figs. 3 and 4). Higher energy costs reduce the prospective return to capital in Annex 1 countries, leading to a drop in investment by agents with foresight. Lower energy prices produce the opposite effect in non-Annex 1 countries.

(No Emissions Trading)

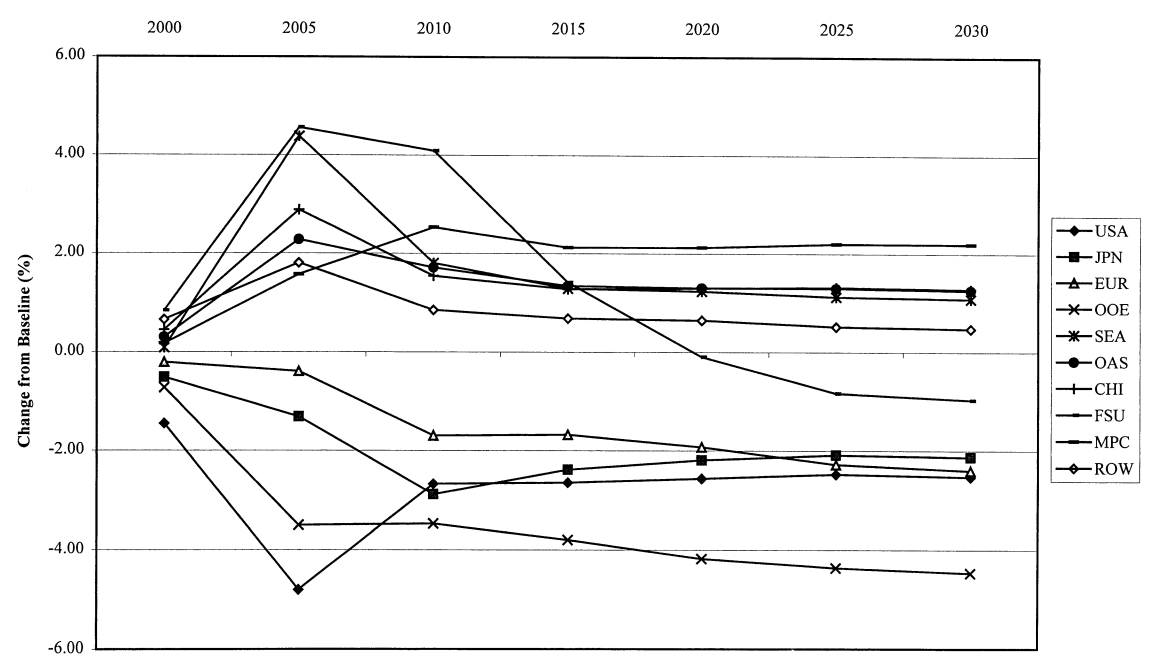

Fig. 3. Total investment (no emissions trading). 


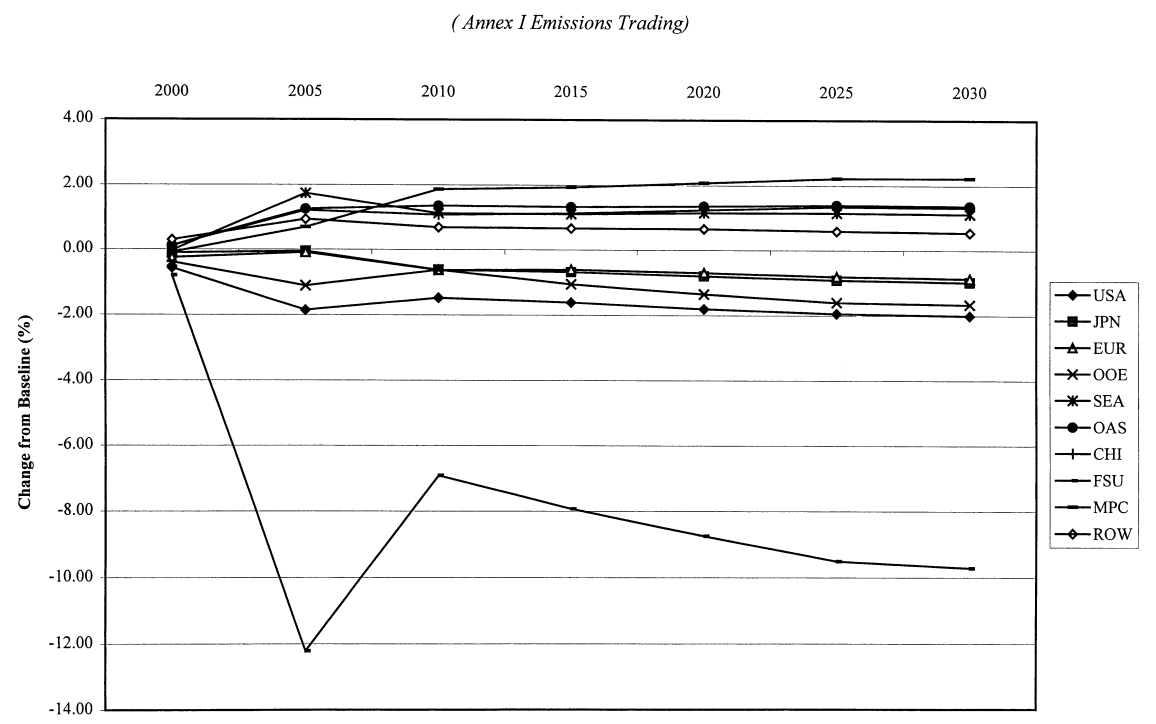

Fig. 4. Total investment (Annex I emissions trading).

Changes in investment are caused by changes in energy cost in Annex 1 countries relative to non-Annex 1 countries. These differences in cost tend to raise the marginal productivity of capital in non-Annex 1 countries and lower it in Annex 1 countries. The immobility of capital across sectors implies that a significant shift in industrial structure must be accompanied by increased gross investment. OPEC, in particular, increases investment in an effort to reduce its exports of oil into a depressed market and to shift into production of energy-intensive goods whose prices increase. Changes in investment are also affected by decisions to reallocate consumption over time, financed in part by changes in domestic saving and partly by changes in international lending. The direction of capital flows will be determined by changes in savings decisions in the different regions and by the demand for capital to change the shares of energy-intensive industries in national output.

In general, Annex 1 trading produces similar but smaller changes in investment. The exception is Russia. With Annex 1 trading, Russia's investment is crushed. In order to gain revenues from permit sales, Russia deindustrializes to generate lower emissions, sell more permits, and live on imports.

With global trading, the picture is reversed for some non-Annex 1 countries. Investment falls relative to baseline in China and India and most other non-Annex 1 regions (see Fig. 5). In general the economies of non-Annex 1 countries are more energy-intensive than Annex 1 countries, and therefore with global trading and uniform permit prices Annex 1 countries are put at a competitive disadvantage 


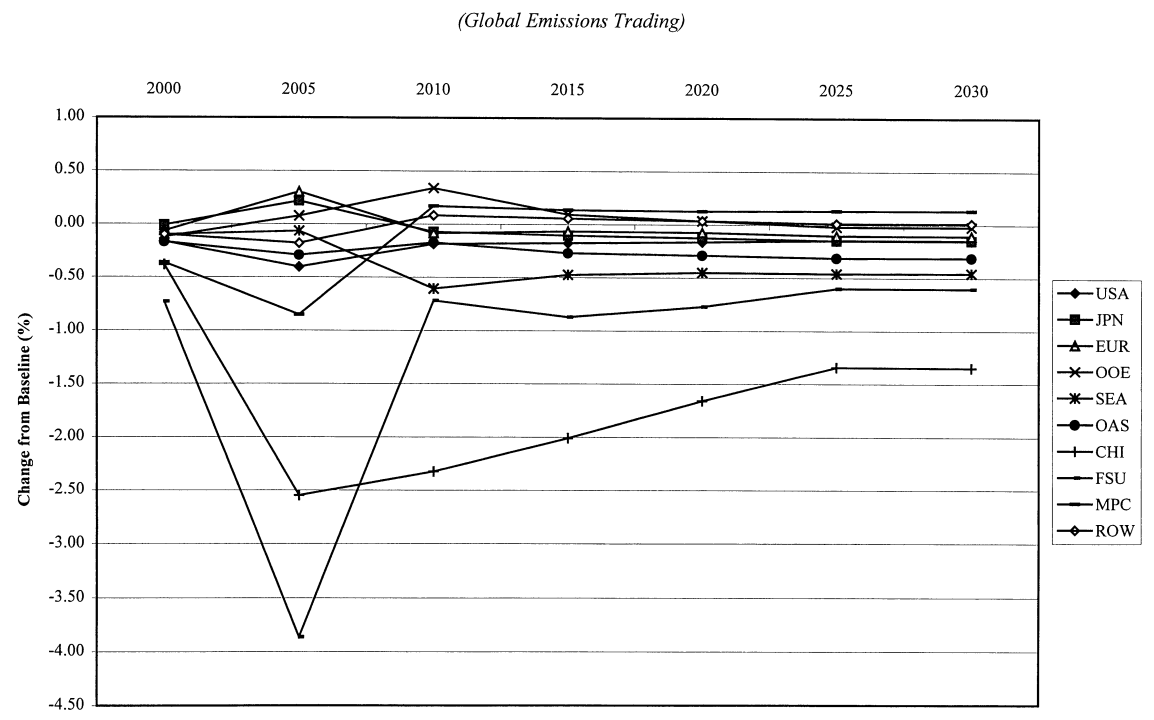

Fig. 5. Total investment (global emissions trading).

and experience a larger reduction in the return to capital than Annex 1 countries. The same effects are found in the output of energy-intensive industries.

\subsection{Changes in industry output}

Changes in industry output are driven by differences in energy and carbon intensity across countries, as well as by differences in permit prices. In 2010 current data on carbon intensities dominate the results. As shown in Table 1, carbon intensities in key industries differ by a factor of 10 or more across regions. EE/FSU, China, and other developing countries typically have far higher levels of carbon emissions per dollar of industry output than the Annex 1 countries, and the US and other OECD countries have about double the carbon intensity of Europe. These patterns are responsible for most of the changes in energy-intensive industry output and investment in 2010. In the later years, the assumed trajectory for autonomous energy efficiency improvement (AEEI) in non-Annex 1 countries becomes more important. In our results, significant differences remain despite faster improvement in AEEI in non-Annex 1 countries (see discussion of benchmarking below). If convergence of energy intensities by 2020 could be achieved, the non-Annex 1 countries would not be placed at as great a competitive disadvantage under global trading.

The relocation of energy-intensive industries from Annex 1 countries to nonAnnex 1 countries when non-Annex 1 countries do not participate in emission trading is significant (see Fig. 6). Annex 1 emission trading moderates this shift by 


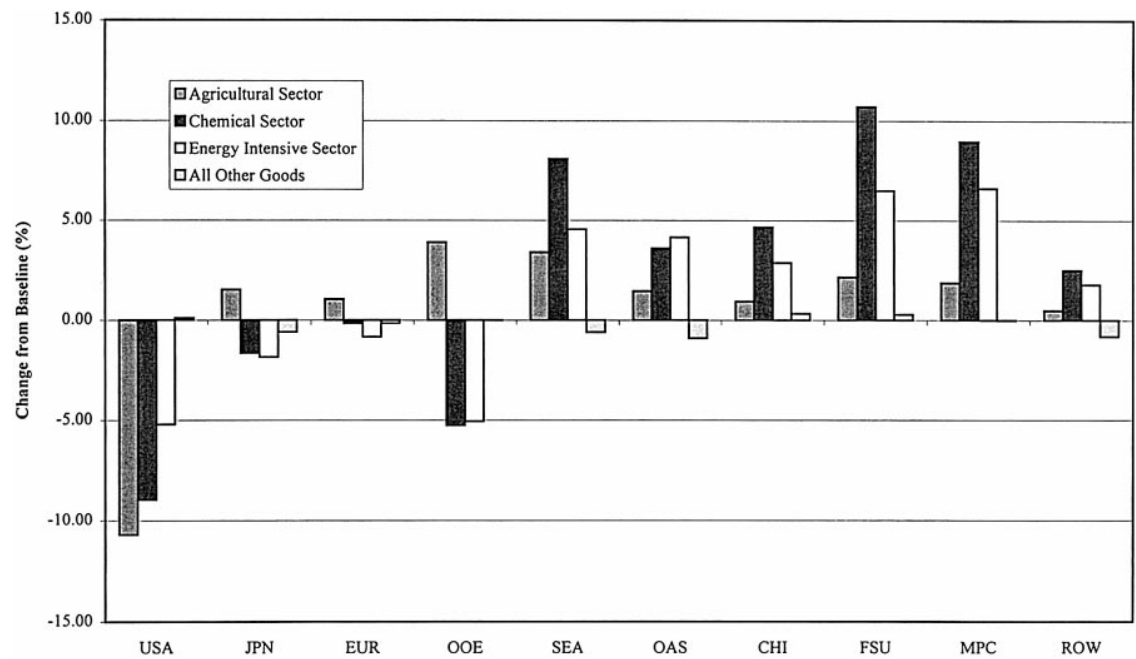

Fig. 6. Sectoral output in 2010 (no emissions trading).

reducing costs to most Annex 1 countries (see Fig. 7). Interestingly, the US and $\mathrm{EE} / \mathrm{FSU}$, which have relatively low permit prices with no international permit trade, proportionally lose the most energy-intensive industry under Annex 1 trading because their energy-intensive industries tend to use more energy per dollar of output than similar industries in other Annex 1 countries.

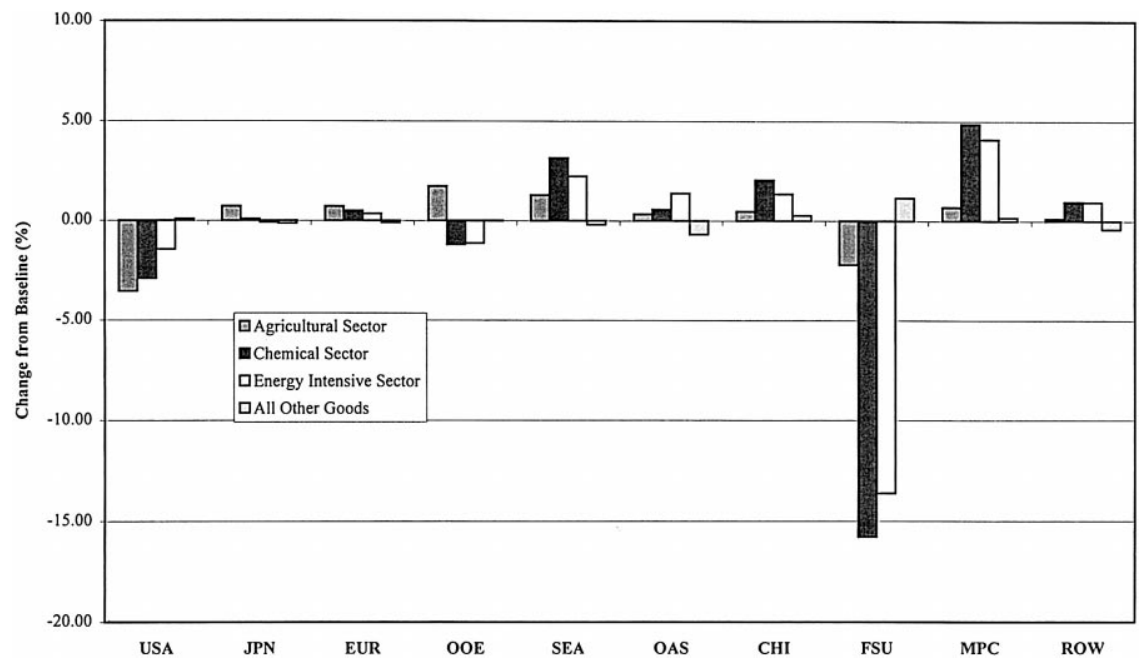

Fig. 7. Sectoral output in 2010 (Annex I emissions trading). 
A striking result is that with global trading, energy-intensive industries exit developing countries. This deindustrialization occurs because of the historically inefficient use of energy (in these industries) in developing countries. The GTAP data show that non-Annex 1 countries have the least energy-efficient industries and therefore are the most vulnerable to a uniform, global increase in energy costs (See Figs. 8 and 9). These countries shift back into a role of providers of raw materials like agriculture.

Surprisingly, these results on how energy-intensive industries shift among regions are robust to different assumptions about Armington elasticities. The Armington elasticity measures how readily imports are substituted for domestically produced goods, and thus measure how much imports are products differentiated from domestic production. It is possible that some of the differences in energy intensity noted above could be due to differences in industry composition, with China, for example, producing more energy-intensive types of chemicals like fertilizers, and the US producing more sophisticated chemicals with higher value added. Reduced Armington elasticities make imports and domestic goods less perfect substitutes, and could in principle change results on industry shifts. Table 9 compares results for industry impacts on the US and China under two different sets of Armington elasticities. Reducing the Armington elasticities between domestic and imported goods from 4 to 1 leaves exactly the same pattern of results in place, with non-Annex 1 countries gaining energy-intensive industries with no permit trading and losing energy-intensive industries with global trading. The magnitude of the shifts is cut approximately in half. The differences in energy intensities, not Armington elasticities, dominate the results.

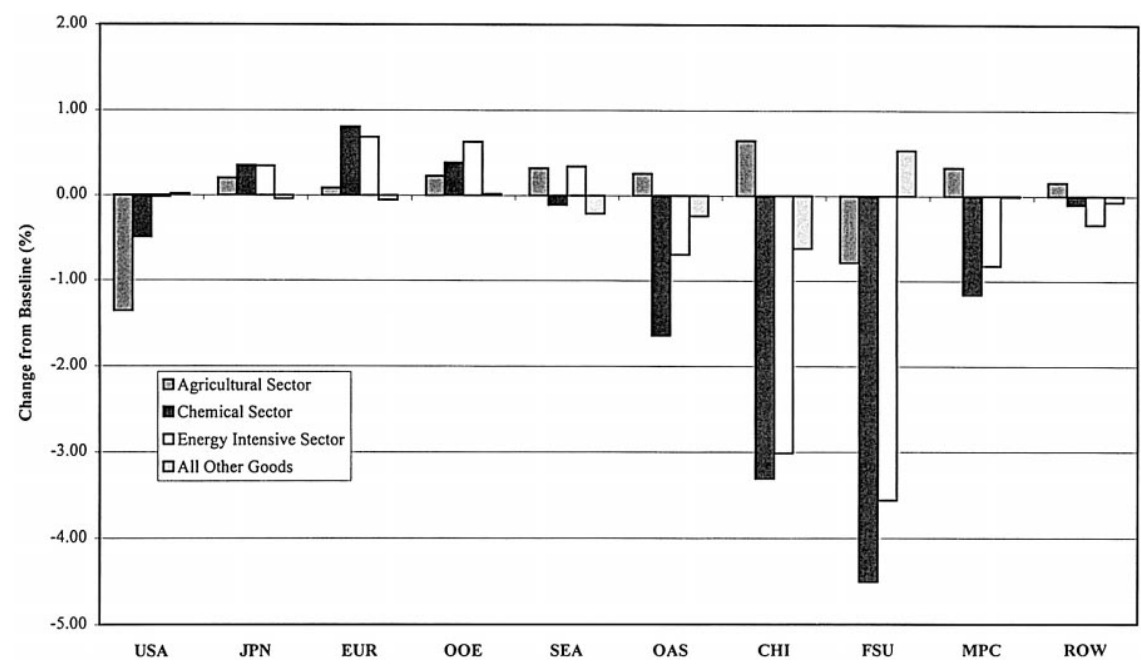

Fig. 8. Sectoral output in 2010 (global emissions trading). 


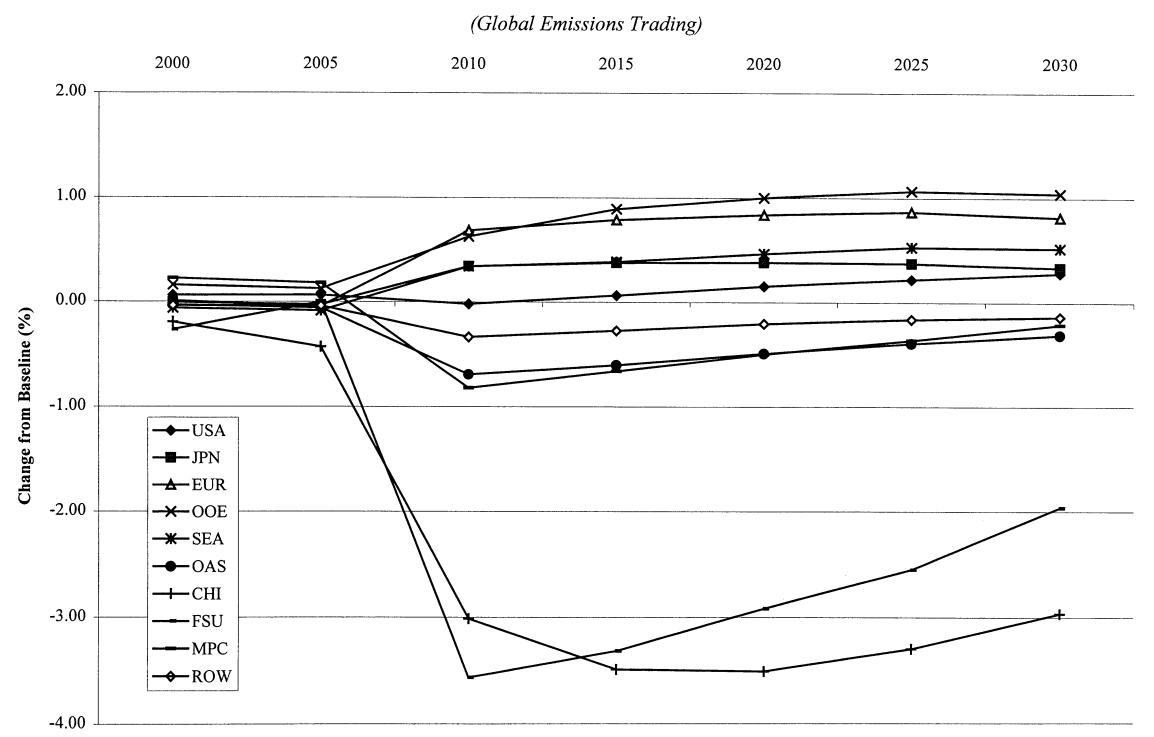

Fig. 9. Output of energy-intensive industries (global emissions trading).

\subsection{Leakage}

The reduction in energy prices in developing countries leads to increased end-use demand for energy, and a shift in the countries toward more energy-intensive industries. This results in carbon leakage, which is a measure of the increase in non-Annex 1 emissions relative to Annex 1 emissions. Significant leakage occurs when there is no international permit trading. It is connected with shifts in energy-intensive industries, reduced energy efficiency, and fuel substitution due to

Table 9

Industry impacts in the US and China (percentage change in industry output for 2010)

\begin{tabular}{lcc}
\hline & Armington elasticities \\
\cline { 2 - 3 } & $\mathrm{dm}-1, \mathrm{~mm}-2$ & $\mathrm{dm}-4, \mathrm{~mm}-8$ \\
\hline Agriculture & -5.45 & -10.68 \\
USA & 0.45 & 0.94 \\
CHI & & \\
Chemicals & -5.18 & -8.96 \\
USA & 1.76 & 4.66 \\
CHI & & \\
& & \\
Energy Intensive & -3.49 & -5.21 \\
USA & 1.27 & 2.87 \\
CHI & & \\
\hline
\end{tabular}


lower fuel prices in developing countries (Fig. 10). Leakage is moderated, but remains, under Annex 1 trading, because energy price increases in Annex 1 countries are moderated. With Annex 1 trading, global emissions also increase and Annex 1 abatement decreases because of hot air sales by EE/FSU, increasing apparent leakage to developing countries in percentage terms.

The choice of Armington elasticities and assumptions about the elasticity of world energy supply (and the implications of this elasticity for the drop in world energy prices under carbon limits) influence these results strongly. Reducing the Armington elasticities would decrease leakage. If goods produced in non-Annex 1 countries are poorer substitutes for goods produced in industrial countries, there will be fewer opportunities for non-Annex 1 countries to take advantage of their lower costs by expanding exports. Raising Armington elasticities would have the opposite effect. Lower values for the elasticity of world energy supply would lead to larger drops in world energy price and hence larger leakage.

The assumption that capital is not mobile across sectors within a country increases the cost of shifting the output mix in non-Annex 1 countries toward energy-intensive goods. With perfectly mobile capital across sectors, it would be even easier for developing countries to specialize in industries where emission limits on industrial countries give them a cost advantage.

Leakage results are robust across all of our sensitivity analysis. Changing baseline emissions growth, demand elasticities, and Armington elasticities all leave leakage in the range of $8 \%$ to $20 \%$ in 2010. The Armington sensitivities, in particular, show that the trade impacts of shifting investment in energy-intensive industries toward developing countries is an important component of leakage. With reduced Armingtons, the shift in energy-intensive industries is cut approxi-

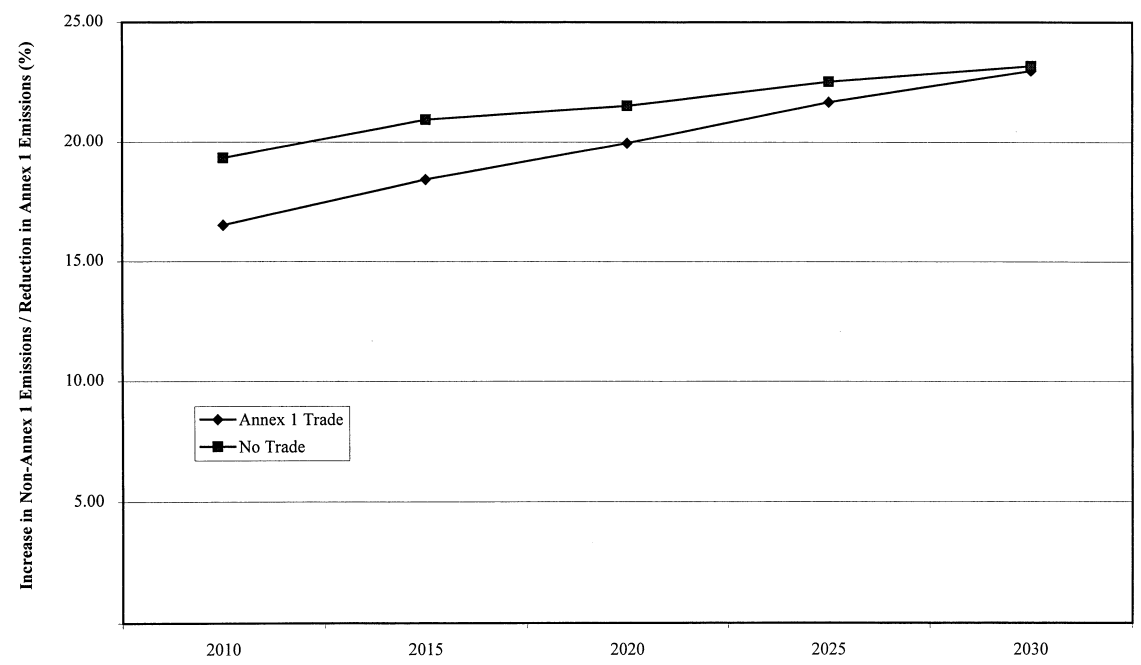

Fig. 10. Carbon leakage. 
mately in half and so is leakage. Higher demand elasticities, which lead to lower carbon taxes in industrial countries and therefore less industry shift, also produce less leakage. The difference in world oil prices across these scenarios, and consequent direct stimulus to greater energy use in developing countries, is too small to contribute much to leakage.

\subsection{Capital flows}

In the MS-MRT model each country faces an intertemporal balance of payments constraint that requires its net foreign indebtedness to be the same in 2030 as in 1995. Capital flows are an important element in trade flows because they make it possible for some countries to lend early in the period by running trade surpluses, and then repay debt later in the period to finance trade deficits. Each borrower is matched by a lender. In particular, in the case of no permit trading, developing countries tend to borrow from industrial countries in 2010 to finance expansion of energy-intensive sectors, while industrial countries lend to developing countries in early periods in order to finance trade deficits in later years when costs increase in the industrial countries. Oil exporting countries also lend early to finance later trade deficits, when their oil revenues disappear.

Capital flows are clearly influenced by a number of factors: time preference, reallocation of consumption over time to recognize future costs, changes in the profitability of investment, and shifts in terms of trade. Anticipation of future costs in a fully dynamic model clearly plays an important role, but subtle assumptions such as those that determine energy/capital complementarity may also play a role.

Basing the model on a representative agent with an intertemporal utility function who makes all choices - including saving and investment - to maximize utility makes it possible to calculate the equivalent variation directly, so that we have a pure welfare measure. Capital flows move in a fashion that is readily explainable in light of intertemporal allocation of consumption and the distribution of cost impacts over time.

Use of the GTAP dataset allows us to identify differences in the structure of world regions, and differences in energy intensities, energy mix, and energy prices that have a strong influence on the trade impacts of climate policies.

The Armington formulation is a general way to incorporate a certain amount of inertia in international markets. Assigning a low elasticity to some goods, such as electricity, ensures realistic shifts in international trade will occur. Likewise, the CES formulation of the Armington aggregate implies that if trade flows are very small in the baseline, they will likely remain small unless there are huge price changes in the policy case. Therefore, trade patterns will remain close to historical levels unless there is a clear cost reason. This helps prevent unrealistic trade in coal and natural gas markets from occurring. We have used Armington elasticities common to general equilibrium modeling of international trade, but recognize that empirical work on these elasticities is scarce. 
The same can be said of the oil, gas, and coal supply elasticities that determine the response of world energy prices to climate policies. We have found in sensitivity analysis with similar models that these two elasticities are critical to the distribution of impacts across regions, and to the question of whether developing countries will gain or lose from Annex 1 emission limits.

\section{Conclusions}

In brief, the MS-MRT consistently finds that imposing emission limits on industrial countries with no international emission trading has negative impacts on the welfare of industrial and some developing countries, including all the oil exporting countries, and positive welfare effects on China and India. Annex 1 trading moderates the impacts, and greatly improves welfare for Russia. Global trading is worse for China and India than no trading, because it removes pecuniary externalities that benefited those regions with limited emission trading. Russia is considerably worse off under global than Annex 1 trading. These findings suggest difficulties in moving the negotiations to implement the Kyoto Protocol forward. Concerns of developing countries about adverse spillover effects of Annex 1 emission limits, raised most recently at the Fourth Conference of the Parties in Buenos Aires, appear to be well-founded. Two countries that have made clear their opposition to participation of developing countries in global trading, China and India, appear to be only voicing their economic self-interest. Russian interest in participating in emission limits could also vanish if full developing-country participation should emerge. Thus the issue of compensation for developing countries is likely to remain open, and at least two countries (China and India), which will account for $25 \%$ of global emissions by 2010 , have reasons for refusing to agree to emission limits without some additional side-payments.

Terms of trade generally move against developing countries and in favor of industrial countries when developing countries do not participate in international emissions trading. This is because industrial countries' costs increase, driving up the price of their exports, and their incomes and import demand fall, driving down the price of their imports. This is the principal reason for the negative impacts on developing countries noted above. Some developing countries can offset these terms of trade losses with industrial countries because of their gains in terms of trade with OPEC and ability to shift to production of energy-intensive goods where they have increased comparative advantage over the industrial countries. This also increases their gains from trade relative to OPEC.

The shift of energy-intensive industries out of Annex 1 countries into non-Annex 1 countries when non-Annex 1 countries do not participate in emission trading is significant. Carbon leakage is also significant, and is connected with shifts in energy-intensive industries, reduced energy efficiency, and fuel substitution due to lower fuel prices in developing countries. Investment falls in all regions, less in non-Annex 1 countries and more in Annex 1 countries. 
Annex 1 emissions trading moderates the shift of industry, by reducing costs to most Annex 1 countries. Interestingly, the US and EE/FSU, the lowest cost providers of permits, lose the most energy-intensive industry under Annex 1 trading.

These results are based on an analysis that takes into account the differences in energy intensity across industries in different countries, and actual data on the share and energy content of imports and exports. They suggest that concern about competitive impacts of implementing emission limits without developing-country commitments is well-founded, and confirm the need for acceptance of emission limits by, at minimum, developing countries responsible for the bulk of non-Annex 1 emissions, and economic activity to avoid competitive distortions and leakage. Full participation by these countries in global emission trading by 2010 is required to avoid significant competitive impacts on industries in the Annex 1 countries.

With global trading, energy-intensive industries move out of developing countries, because the GTAP data show that those countries have the least energy-efficient industries and therefore are the most vulnerable to a uniform, global increase in energy costs. Unfortunately, this deindustrialization is likely to reduce the enthusiasm of these countries for global emission trading even if they benefit in the long run from permit revenues that allow substitution of imports for domestic industrial activity. In our global trading scenario, emission limits for non-Annex 1 countries are set at a level that allows for baseline emissions growth plus leakage. Larger transfers from industrial countries to developing countries than implied by these limits could be required.

\section{Acknowledgements}

The authors are indebted to Edward Balistreri, Lynn Yang, and David Wilson for their contributions to this paper, and to participants in the NBER Snowmass Workshop for their comments on an earlier version of the paper. Research support from the Business Roundtable and the Electric Power Research Institute is gratefully acknowledged. All conclusions in the paper are the sole responsibility of the authors.

\section{Appendix A. The model}

This section offers an algebraic description of the important elements of the MS-MRT model: production, international trade, consumption, investment, and savings. The purpose of this section is to document the functional forms which characterize preferences and technology. We also present the conditions which characterize an Arrow-Debreu equilibrium as a nonlinear complementarity prob- 
lem, following Mathiesen (1985). In the following, special attention is devoted to the nature of energy demand by firms and consumers, which is represented by nested constant-elasticity-of-substitution utility functions and production functions. Apart from the special treatment of energy demand, the model is largely based on the GTAPinGAMS equilibrium model (Rutherford, 1998b), particularly in the modeling of international trade flows and preferences.

\section{A.1. Production of the non-energy good}

There are four non-energy production sectors in MS-MRT. In producing these goods, the model accounts for regional differences in factor intensities, degrees of factor substitutability, and the price elasticities of output demand in order to trace back the structural change in industrial production that is induced by carbon abatement policies.

\section{A.2. Industry production}

All non-energy industries have a similar production structure. Materials (outputs of the four industries used as inputs in other industries) enter the production function in fixed proportion:

$$
M_{i j r t}=a_{i j r}^{M} Y_{j r t}
$$

Output is also determined by a constant-elasticity aggregate of value added and energy:

$$
Y_{j r t}=\phi_{j r}\left[\alpha_{j r}^{E} E_{j r t}^{\rho}+\left(1-\alpha_{j r}^{E}\right) V_{j r t}^{\rho}\right]^{1 / \rho}
$$

The value added aggregate $\left(V_{j r t}\right)$ comprises capital and labor. When the energy value share of an industry $\left(\alpha_{j r}\right)$ is small, the elasticity of substitution between the value added aggregate and the composite energy good $\left(\sigma_{j r t}=1 /\left(1-\rho_{j r t}\right)\right)$ is nearly equal to the own price elasticity of demand for energy. This elasticity determines how difficult or easy it is for a region to adjust its production processes in response to changes in energy prices. Higher values of the energy substitution elasticity imply that a region can more easily substitute value added for energy as the price of energy increases. This elasticity is time-varying to reflect capital stock turnover and the case of deploying new technology. For OECD countries, this elasticity begins at a value of 0.25 in the year 2000 and rises linearly to 0.5 by 2030; in non-OECD countries, it starts at 0.2 and rises linearly to 0.4 over the 30 year time horizon.

Capital and labour are combined in a Cobb-Douglas production function to characterize value-added:

$$
V_{j r t}=K_{j r t}^{\theta_{j r}} L_{j r t}^{1-\theta_{j r}}
$$


In this composite capital and labor may be substituted directly for each other through activities such as the automation of labor-intensive tasks. Therefore, the higher the wage rate, the more attractive it becomes to adopt automation.

Labor inputs in this model are measured in efficiency units, so that one unit of labor supply is the same as 10 billion dollars of base year wages. Labor supply is exogenous. Total labor endowment for each region increases over time with labor force efficiency along the region's baseline growth assumptions. All labor is regionally immobile, and the labor force is fully employed. The model has a long-term perspective and does not incorporate unemployment and labor-leisure decisions.

Capital stocks evolve through geometric depreciation of existing capital stocks and new investment of fully mobile capital (within countries). The rates of return on capital are determined in an international market by endogenous levels of lending and borrowing. We assume perfectly competitive capital markets in which the rate of return adjusts so that supply equals demand. The model is calibrated to an equalized net rate of return equal to $5 \%$ in all regions.

Material inputs are complements among each other, all other inputs are substitutes. Each intermediate input in turn represents a composite of domestic and imported varieties, with value shares determined by relative prices-intermediate inputs from domestic industry $j$ are imperfect substitutes for imports of good $j$.

\section{A.3. Industrial energy demand}

Energy inputs to production represent a composite of electric and non-electric carriers. Non-electric inputs are in turn a composite of coal and liquid fuels. Finally, liquid fuels are a composite of gas and oil. We use precisely this hierarchical structure in the production function itself. We begin by expressing energy inputs as a composite of electric and non-electric inputs:

$$
E_{j r t}=\phi_{j r}^{E}\left[\alpha_{j r}^{E} \mathrm{EL}_{j r t}^{\rho_{E}}+\left(1-\alpha_{j r}^{E}\right) \mathrm{NE}_{j r t}^{\rho_{E}}\right]^{1 / \rho_{E}}
$$

and non-electric inputs are a nested CES aggregate of coal, gas, and oil inputs:

$$
\begin{aligned}
\mathrm{NE}_{j r t}= & \phi_{j r}^{\mathrm{N}}\left\{\alpha_{j r}^{\mathrm{C}} \mathrm{COAL}_{j r t}^{\rho_{\mathrm{C}}}+\left(1-\alpha_{j r}^{\mathrm{C}}\right)\left[\alpha_{j r}^{\mathrm{G}} \mathrm{GAS}_{j r t}^{\rho_{\mathrm{G}}}\right.\right. \\
& \left.\left.+\left(1-\alpha_{j r}^{\mathrm{G}}\right) \mathrm{OIL}_{j r t}^{\rho_{\mathrm{G}}}\right]^{\rho_{\mathrm{C}} / \rho_{\mathrm{G}}}\right\}^{1 / \rho_{\mathrm{C}}}
\end{aligned}
$$

A hierarchical structure of demand admits two elasticities which govern interfuel substitution. $\sigma_{j r}^{\mathrm{C}}=1 /\left(1-\rho_{\mathrm{C}}\right)$ determines the ease with which coal can substitute for liquid fuels, and $\sigma_{j r}^{\mathrm{G}}=1 /\left(1-\rho_{\mathrm{G}}\right)$ determines the potential for substitution between oil and gas. 


\section{A.4. Export markets}

Production of each good may be supplied either to domestic or export markets:

$$
Y_{j r t}=D_{j r t}+X_{j r t}
$$

The model incorporates international markets for all goods. For these goods, we have a global market clearing condition:

$$
X_{j r t}=\sum_{s} M_{j r s t}
$$

in which $r$ and $s$ both index regions in the model.

\section{A.5. Production of fossil fuels}

The production of fossil fuels requires inputs of the aggregate non-energy good and a fuel-specific input that can be thought of as a sector-specific resource.

$$
S_{f r t}=\phi_{f r}^{S}\left[\alpha_{f r t} \bar{R}_{f r t}^{\rho}+\left(1-\alpha_{f r t}\right) X_{f r t}^{\rho}\right]^{1 / \rho}
$$

In this expression, $X_{f \underline{r} \underline{t}}$, represents inputs of the aggregate non-energy-intensive good. The fixed input, $\vec{R}_{f r t}$, is a specific factor which provides positive profits (rents) to owners of the fixed factor, the representative agent in region $r$.

There are four parameters in the production function for fossil fuels. Three of these (the output scale factor $\left(\phi_{f r}^{S}\right)$, the resource value share $\left(\alpha_{r f t}\right)$ and the resource supply $\left(\bar{R}_{f r t}\right)$ are selected jointly to match fossil fuel production along the baseline growth path to the US Department of Energy's projections for fossil fuel production (DOE, 1998) through 2020 and to the IPCC IS29 a scenario from 2020 to 2030. One free parameter, the elasticity of substitution between the resource and other inputs $\left(\sigma_{f r t}=1 /\left(1-\rho_{f r t}\right)\right)$, is then selected to calibrate the model to an exogenously specified time-varying elasticity of supply along the baseline.

\section{A.6. Consumer choice and the representative agent}

Aggregate demand within each region is represented through the intertemporal choice of a representative agent who allocates regional income across consumption in different time periods in order to maximize welfare. In each period, the consumer faces the choice between current consumption and future consumption that is purchased via savings. A pure rate of time preference between current and future consumption determines the intertemporal allocation of consumption. In equilibrium, the agent is indifferent between consuming one unit of consumption today or consuming the value of one unit of consumption that is adjusted for time 
preference tomorrow. We employ an intertemporal separable utility function of the form:

$$
U_{r}=\sum_{t=2000}^{2030} \delta_{r t} \frac{C_{r t}^{1-\theta}-\theta}{1-\theta}
$$

in which $\theta$ is the inverse of the elasticity of intertemporal substitution, and $\delta_{r t}$ accounts for discounting of future consumption. Each region's representative agent maximizes intertemporal utility subject to an intertemporal budget constraint:

$$
\max U_{r}\left(C_{r t}\right)
$$

s.t.

$$
\sum_{t} p_{r t}^{C} C_{r t}=\sum_{t} w_{r t} \bar{L}_{r t}+\sum_{i} p_{i r 0}^{K} K_{i r 0}+\sum_{f, t} p_{f r t}^{R} \bar{R}_{f r t}+\sum_{t} T_{r t}-\sum_{i} p_{i r T+1} K_{i r T+1}
$$

In the maximization problem the budget constraint equates the present value of consumption demand to the present value of wage income, the value of the initial capital stock, the present value of rents on fossil energy production, the value of tax revenue through the model horizon, less the value of capital stock in period $T+1$.

Within each period, consumption demand is an aggregate of energy and non-energy goods within a constant-elasticity of substitution utility function:

$$
C_{r t}=\left[\alpha_{r}^{C}\left(\prod_{i} c_{i r t}^{\theta_{i r}}\right)^{\rho}+\left(1-\alpha_{r}^{C}\right) \mathrm{EC}_{i r t}^{\rho}\right]^{1 / \rho}
$$

\section{A.7. End-use energy demand}

Aggregate end-use energy $\left(\mathrm{EC}_{i r t}\right)$ is composed of an aggregate of electricity, oil, gas, and coal. These fuels substitute against each other with elasticities of substitution characterizing the trade-off of electric for non-electric, coal for liquids, and oil for natural gas, using functional forms analogous to those used in industrial energy demand.

\section{A.8. Foreign trade}

There is international trade in fossil fuels and non-energy goods. Bilateral trade flows for the non-energy good are represented through Armington composites as in the GTAPinGAMS model (Rutherford, 1998b). In energy markets, gas, electricity, and coal are represented as regionally differentiated products. Only crude oil is represented as a homogeneous product, sold in a unified world market.

The key idea in our representation of international trade with differentiated products is that small cost differences across regions for a given good do not lead 
to a total shift in demand from one region to another, and small changes in costs lead to small movements away from existing trade patterns. In addition, the Armington structure accommodates both imports and exports of the same commodity across regions (cross-hauling).

When consumers and industries choose between these domestically produced goods and imports, they respond to relative prices. Compensated demands for domestic and imported products arise from constrained minimization problems of the form:

$$
\min p_{D} D+p_{M} M
$$

s.t.

$$
\left[\alpha_{D} D^{\rho_{D M}}+\left(1-\alpha_{D}\right) M^{\rho_{D M}}\right]^{1 / \rho_{D M}}=A
$$

where $A$ is a given quantity of the Armington aggregate demanded. The composition of bilateral trade in a given good is then determined by a constrained minimization problem of the form:

$$
\min \sum_{r} p_{r}^{M} m_{r}
$$

s.t.

$$
\left[\sum_{r} \alpha_{r}^{M} m_{r}^{\rho_{M M}}\right]^{1 / \rho_{M M}}=M
$$

Within this formulation domestically produced goods are differentiated from imports with an elasticity of substitution $\sigma_{D M}=1 /\left(1-\rho_{D M}\right)$, and imports from one region are differentiated from imports from another region with an elasticity of substitution $\sigma_{M M}=1 /\left(1-\rho_{M M}\right)$. We typically choose elasticities such that imported goods from two different sources are closer substitutes than are aggregate imports and domestic goods, i.e., $\sigma_{D M}<\sigma_{M M}$.

\section{A.9. Capital flows}

The budget constraint in final demand relates the present value of consumption to the present value of factor income. There are no restrictions on capital flows within a given period. It is an accounting identity that the difference between the value of imports and the value of exports in any given period equals the difference between the value of aggregate demand (consumption plus investment) and the value of factor income (labor, capital, energy resources, and taxes):

$$
\begin{aligned}
\kappa_{r t} & =\sum_{i s}\left(p_{i s t} m_{i s r t}-p_{i r t} m_{i r s t}\right) \\
& =p_{r t}^{C} C_{r t}+p_{r t}^{I} I_{r t}-w_{r t} \bar{L}_{r t}-\sum_{i} r_{i r t}^{K} K_{i r t}-\sum_{f} p_{f r t}^{R} \bar{R}_{f r t}-T_{r t}
\end{aligned}
$$


One country runs a current account deficit only if all other countries run a net surplus, i.e.:

$$
\sum_{r} \kappa_{r t}=0
$$

Furthermore, it follows from the consumer budget constraint that there is no net change in indebtedness over the model horizon, i.e. ${ }^{4}$

$$
\sum_{t} \kappa_{r t}=0
$$

\section{A.10. Savings and investment}

MS-MRT is essentially a Ramsey model in which representative agents make explicit decisions about the time path of consumption, while investments are undertaken by competitive firms which arbitrage current investments against future returns. All investments are forward-looking, and agents anticipate the effects of announced policies that are to take effect in the future.

Sectoral capital stocks depreciate at a constant geometric rate, and they are incremented by investment from domestic output. With 5-year time periods, the transition equation for the capital stock in sector $i$ is:

$$
K_{i r t+5}=\lambda_{i r} K_{i r t}+3 I_{i r t}+2 I_{i r t+1}
$$

in which we assume a two year gestation lag for capital investment and a uniform pattern of investment within a given 5-year period; hence, if $I_{\text {irt }}$ is the rate of investment in year $t$, then $2 I_{\text {irt }}$ units of capital enter the current capital stock and $3 I_{i r t}$ are delivered in the next period.

The capital evolution equation assumes a 5-year capital survival share of $\lambda=(1-\delta)^{5}$ where $\delta$ is the annual depreciation rate.

Let $p_{r t}^{I}$ represent the unit cost of investment and $p_{i r t}^{K}$ represent the price of capital. The no-arbitrage condition for investment in sector $i$ is then:

$$
p_{r t}^{I}=2 p_{i r t}^{K}+3 p_{i r t+1}^{K}
$$

\section{A.11. Approximating the infinite horizon}

Numerical models can only be solved for a finite number of periods, and the finite horizon poses some problems with respect to capital accumulation. In the

\footnotetext{
${ }^{4}$ This closure is consistent with conventional neoclassical economics, and it is exactly analogous to the Global 2100 model, (Manne and Richels, 1992). This formulation distinguishes our model from G-Cubed (McKibbin and Wilcoxen, 1995), which imposes a constraint on period-by-period capital flows. Furthermore, it seems that in G-Cubed a region's net foreign indebtedness can change over the model time horizon. G-Cubed accounts for the effects of changes in indebtedness by calculating GNP, in which interest payments on foreign debt are deducted from domestic output (GDP).
} 
absence of any terminal adjustment, agents would consume all capital stock in the terminal period and thus let the value of the capital stock decline to zero after 2030. We therefore need to make some adjustments in the specification in order to produce a model which when solved over a finite horizon approximates the infinite horizon choices. We do this by imposing a steady-state condition in the model's terminal period.

We do this by introducing an additional variable to the model for each capital stock in the model. The post-terminal capital stock in sector $i$ is given by $K_{i r T+1}$, and the associated equilibrium condition is a constraint on the growth rate of sectoral investment in the terminal period:

$$
\frac{I_{i r T}}{I_{i r T-1}}=\frac{C_{i r T}}{C_{i r T-1}}
$$

Note that terminal capital stocks are 'purchased' by the representative agent in region $r$, and these expenditures therefore appear in the budget constraint.

The equilibrium conditions associated with terminal capital stocks $K_{i r T+1}$ enter as equations along with all other economic equilibrium conditions (zero profit, market clearance, and income balance), but the application of this constraint has no direct implications for investment and consumption activities because the terminal capital stock does not enter into the zero-profit conditions for these activities. Instead, we close the model by including a terminal capital stock variable, the quantity of which is determined in order that the rate of growth of terminal investment is balanced. That is, the shadow price of the above auxiliary constraint is the price of the terminal capital stock. (See Rutherford et al., 1998 for further details.)

\section{A.12. Carbon restrictions}

To comply with the Kyoto Protocol, the model places a carbon emissions limit on the participating countries. The model endows these countries with emissions permits that allow them to emit carbon up to the level to which they agreed. In the MS-MRT model, it is assumed that, under the no trade scenario, the emissions permits are tradable within each Annex 1 region but not across regions. Under the trading scenarios, emissions permits can be traded among the different blocs: for the Annex 1 trading scenario, only Annex 1 countries face carbon limits, and the permits are tradable across all Annex 1 countries; for the global trading scenario, all countries face carbon limits, and the permits are tradable throughout the world.

The carbon permits allow the participating countries to determine the most economically efficient method of reducing their carbon emissions. If commandand-control or specific carbon reduction strategies that regulated only specific industries were used, then the marginal cost of reducing carbon emissions would be greater. 
Placing a cap on a country's carbon emissions is mathematically equivalent to having a country adopt a per-ton carbon tax and return the revenues to the economy in lump sum. The shadow price on the emissions constraint equals the marginal cost to reduce carbon emissions. This is equivalent to the carbon tax required for a country to reduce its emissions by the amount that the proposals mandate. Therefore, the model would obtain the same equilibrium solution if a country applied a carbon tax that equaled the marginal cost of the emissions permit or issued emissions permits. Because of this, the carbon tax also represents the lowest possible marginal cost of reducing carbon emissions under the assumption that revenues from the carbon tax are refunded lump-sum to the economy, appearing as $T_{r t}$ in the budget constraint.

\section{Appendix B. Benchmarking and calibration}

As is customary in applied general equilibrium analysis, the MS-MRT model is benchmarked to economic transactions in a particular year (1995). Benchmark data determine the parameters and coefficients (value shares) of the CES production, demand, and utility functions. Base-year finance statistics indicate the value of payments to capital across sectors and the gross value of capital formation. For calibration, we needed to determine a reference level of emissions growth, GDP growth, energy production, energy, and non-energy trade. This entailed assigning values to key elasticities, such as end-use demand, Armington, and oil supply, and the Autonomous Energy Efficiency Improvement (AEEI).

The model is based on a consistent database for energy and non-energy trade and input-output data which merges non-energy trade data, input-output data, and input-output coefficients for energy from the GTAP database with data from the International Energy Agency (IEA). Prices and quantities of all non-energy data are based on the 1995 GTAP Version 4 database from Purdue University, with significant changes to energy prices and intensities). This database provides trade and production statistics for 50 regions and 45 commodities for the year 1995; it was aggregated into energy and non-energy goods for the eight regions. The IEA database provides energy production and consumption, as well as price data in the production, industry, and final consumption sectors electric and non-electric energy. In our benchmark data, the IEA energy data (prices and quantities) replace the GTAP energy data. The IEA database was used to determine the benchmark levels of energy prices and quantities.

For carbon emissions forecasts, the model was calibrated to the projections of both DOE and the International Panel on Climate Control. The reference or business as usual (BAU) level growth path for world emissions is taken to be the IPCC's reference scenario IS92A. The IS92A scenario corresponds to the IPCC's baseline (medium growth) scenario, which calls for worldwide carbon dioxide emissions to grow from 6 billion metric ton in 1990 to 10.7 billion metric tons by 
the year 2025. The reference level emissions growth determines the amount of emissions reduction required to meet the carbon limits called for by any carbon abatement policy.

The energy production and consumption forecasts as well as regional emissions were obtained from the DOE International Energy Outlook, 1998. These forecasts were then calibrated to current EIA data and the IS92A scenario so that energy consumption was consistent with and carbon emissions. The business-as-usual GDP growth rates were taken from MERGE (a Model for Evaluating the Regional and Global Effects of greenhouse gas reduction policies), which was developed by Alan Manne and Richard Richels. Table 10 shows the assumptions of GDP growth rates as a function of time for the seven MS-MRT regions.

To match the MERGE GDP growth forecasts to the DOE's forecasted change in energy prices and growth in energy consumption, the model uses a parameter called Autonomous Energy Efficiency Improvement (AEEI). AEEI reflects the rate of improvement in energy efficiency independent of any future energy price changes. This parameter allows a region or country's GDP growth rate to differ from its growth rate in energy consumption without any changes in relative prices. That is, the energy share of GDP varies without any price changes between energy and non-energy goods in accordance with the AEEI.

\section{B.1. Elasticity values and backstop prices}

Selecting elasticity values affects the baseline dynamics of the model and how the model responds under a carbon abatement policy. These values, however, have no effect on replicating the benchmark year. There are several key elasticities that need to be chosen for an MS-MRT simulation, including the oil supply price elasticity, Armington elasticity, end-use demand elasticity, interfuel elasticity of substitution, and the cost of the carbon-free backstop technology.

Table 10

GDP growth rates (percent per annum)

\begin{tabular}{lrllllll}
\hline Region & 2000 & 2005 & 2010 & 2015 & 2020 & 2025 & 2030 \\
\hline USA & 2.7 & 2.7 & 2.4 & 2.2 & 2.0 & 1.9 & 1.8 \\
JPN & 2.1 & 2.1 & 2.2 & 2.1 & 1.9 & 1.9 & 1.8 \\
EUR & 2.2 & 2.2 & 2.2 & 2.1 & 2.0 & 1.9 & 1.8 \\
OOE & 2.3 & 2.3 & 2.3 & 2.3 & 2.3 & 2.3 & 2.3 \\
SEA & 3.8 & 3.9 & 5.5 & 5.0 & 5.0 & 4.5 & 4.5 \\
OAS & 4.9 & 4.9 & 5.3 & 5.0 & 5.0 & 4.5 & 4.5 \\
CHI & 5.7 & 5.7 & 5.3 & 5.0 & 5.0 & 4.5 & 4.5 \\
FSU & -2.8 & 3.5 & 3.5 & 3.5 & 3.4 & 3.1 & 2.8 \\
MPC & 3.4 & 3.4 & 3.9 & 3.8 & 3.8 & 3.6 & 3.6 \\
ROW & 3.7 & 3.8 & 3.8 & 3.8 & 3.8 & 3.3 & 3.3 \\
\hline
\end{tabular}


The supply elasticity for energy determines how world energy prices respond to changes in world energy demand. The supply elasticity for oil functions similarly with respect to world oil demand. A value of 1.0 was chosen for the oil price supply elasticity. This implies that a $1 \%$ change in the quantity demanded results in a $1 \%$ price change. Increasing the oil price response will cause energy-exporting nations to suffer more when a carbon abatement policy is enacted. On the other hand, higher oil price responses lead to greater benefits for the oil-importing countries. Values of 4 and 1 were chosen for the gas and coal price supply elasticities, respectively.

The Armington elasticity determines how easily a country can trade imported goods for domestically produced goods. The elasticity also determines how much of one region's domestically produced goods would be displaced by another region's imports when a carbon abatement policy is put in place. The Armington elasticity was set equal to 4 in the reference scenario. Armington elasticities for combining regional imports into a single import commodity for each industry are set equal to 8. Electricity is given a much higher Armington elasticity to minimize trade across countries. Armington elasticities are consistent with those used in other trade studies based on computable general equilibrium models. (See Martin and Winters, 1996).

The end-use demand elasticity determines the substitution between energy and other factors in production and consumption. Thus, this parameter determines how total energy demand responds to increases in the price of energy in both the short and long runs. To model the idea that this elasticity should increase over time, we assume a lower short-run value for the year 2000, a higher long-run value for the year 2030, and a linear increase from the short-run to the long-run value over the 30 -year time horizon. For OECD countries, the short- and long-run values equal 0.25 and 0.5 , respectively. Because the non-OECD countries are less developed than the OECD countries, they are assumed to have lower values for the end-use demand elasticity: values of 0.2 and 0.4 are used for the short and long runs, respectively (these values are within the range suggested in Linbeck, 1998).

The interfuel elasticity of substitution determines how easily oil, gas, and coal substitute for one another. This elasticity affects the costs of switching fuels to reduce carbon emissions. For these simulations, the interfuel elasticity is set equal to one. This implies that if the price of one fuel-coal, for example-increases by $1 \%$ and the other two fuel prices and the total quantity of energy demanded remains unchanged, then the quantity of coal consumed decreases by one $\%$ and consumption of the other two fuels would increase to cover the drop in coal consumption.

In addition to the three fossil fuels, the MS-MRT includes a carbon-sequestration activity that can reduce carbon emissions from fossil fuels. This activity is referred to as the carbon backstop and is available at constant cost. Since this alternative is unavailable today, though it is believed to be available in the future, its price is assumed to be more expensive than the current fossil energy aggregate. The backstop price sets an upper limit on the cost of reducing carbon emissions in 
countries that adopt commitments because countries can use this fuel to satisfy all their energy needs. For the reference case, the backstop is assumed to cost US\$500/ton in Annex 1 regions. The backstop is produced from the Armington aggregate of all other goods.

\section{B.2. Baseline growth}

The business as usual (BAU) case is a computed equilibrium in which regions grow a non-uniform rates over the 30-year horizon. In order to track with the assumed GDP growth rates, we change labor endowments over the time horizon so that potential GDP growth equals the assumed rate in each time period. Capital flows are limited in the BAU case because we have time-varying discount rates for each region which match assumed consumption growth rates to a uniform $5 \%$ interest rate. In the absence of changes in relative prices, there is no economic incentive for capital flows in the BAU. However, when we solve for the BAU case, differences in GDP growth rates over time induce changes in the terms of trade, and this leads to moderate capital flows. (See Manne and Rutherford, 1994 for a discussion of these issues).

To compute the impacts of the Kyoto Protocol, the MS-MRT model is first run under the BAU scenario that includes the above set of elasticity values and assumptions. Using these same assumptions, the model is then run with the Kyoto Protocol's carbon limits on the Annex 1 countries. This solve is referred to as the counterfactual. The percentage change numbers that are reported in this chapter reflect the percentage change between the BAU and the counterfactual.

\section{References}

Armington, P., 1969. A theory of demand for products distinguished by place of production. IMF Staff Papers 16, 159-178.

Babiker, M., Maskus, K., Rutherford, T.F., 1997. Carbon taxes and the global trading system, Working Paper. Department of Economics, University of Colorado.

Berstein, P.M., Montgomery, W.O., Rutherford, T.F., Yang, G.F., 1999. Effects of Restrictions on International Permit Trade. The MS-MRT Model. The Energy Journal (forthcoming).

US Department of Energy; Energy Information Administration, 1998. International Energy Outlook 1998. DOE/EIA-0383(98), Washington, DC.

Hertel, T.W. (Ed.), 1997. Global Trade Analysis: Modeling and Applications. Cambridge Univ. Press, Cambridge.

Linbeck, A., 1998. The Recent Slowdown of Productivity Growth. Economic Journal.

Manne, A.S., Rutherford, T.F., 1994. In: Cooper, W.W., Whinston, A.B. (Eds.), International Trade, Capital Flows and Sectoral Analysis: A Formulation and Solution of Intertemporal Equilibrium Models. New Directions in Computational Economics, pp. 191-205.

Manne, A.S., Richels, R.G., 1992. Buying Greenhouse Insurance-The Economic Costs of Carbon dioxide Emission Limits. MIT Press, Cambridge.

Martin, W., Winters, L.A. (Eds.), 1996. The Uruguay Round and the Developing Countries. Cambridge Univ. Press, Cambridge. 
Mathiesen, L., 1985. Computation of Economic Equilibrium by a Sequence of Linear Complementary Problems, Mathematical Programming Study, Vol. 23. Amsterdam, North-Holland, pp. 144-162.

McKibbin, W.J., Wilcoxen, P.J., 1995. The theoretical and empirical structure of the G-Cubed model, Working Paper. The Brookings Institution.

Rutherford, T.F., 1998a. GTAPinGAMS: Tools for Energy-Economy Modeling, Working Paper. University of Colorado, Department of Economics.

Rutherford, T.F., 1998b. GTAPinGAMS: the dataset and static model, Working Paper. University of Colorado, Department of Economics.

Rutherford, T.F., Lau, M., Pahlke, A., 1998. A Primer in Dynamic General Equilibrium Analysis. Working Paper, University of Colorado, Department of Economics. 